This item was submitted to Loughborough's Research Repository by the author.

Items in Figshare are protected by copyright, with all rights reserved, unless otherwise indicated.

\title{
The Epstein-Zin model with liquidity extension
}

\section{PLEASE CITE THE PUBLISHED VERSION}

http://dx.doi.org/10.1111/fire.12098

\section{PUBLISHER}

(c) The Eastern Finance Association. Published by Wiley

\section{VERSION}

AM (Accepted Manuscript)

\section{PUBLISHER STATEMENT}

This work is made available according to the conditions of the Creative Commons Attribution-NonCommercialNoDerivatives 4.0 International (CC BY-NC-ND 4.0) licence. Full details of this licence are available at: https://creativecommons.org/licenses/by-nc-nd/4.0/

\section{LICENCE}

CC BY-NC-ND 4.0

\section{REPOSITORY RECORD}

Liu, Weimin, Di Luo, and Huainan Zhao. 2019. "The Epstein-zin Model with Liquidity Extension”. figshare. https://hdl.handle.net/2134/24079. 


\title{
The Epstein-Zin Model with Liquidity Extension
}

\author{
Weimin Liu \\ Nottingham University Business School China and Shanxi University \\ Di Luo* \\ Swansea University \\ Huainan Zhao \\ Cranfield University School of Management
}

\begin{abstract}
In this paper, we extend the Epstein and Zin $(1989,1991)$ model with liquidity risk and assess the extended model's performance against the traditional consumption pricing models. We show that liquidity is a significant risk factor, and it adds considerable explanatory power to the model. The liquidity-extended model produces both a higher cross-sectional $R^{2}$ and a smaller Hansen and Jagannathan (1997) distance than the traditional consumption-based capital asset pricing model (CCAPM) and the original Epstein-Zin model. Overall, we show that liquidity is both a priced factor and a key contributor to the extended Epstein-Zin model's goodness-of-fit.
\end{abstract}

JEL classification: G12; G14

Keywords: Liquidity risk; Consumption-based asset pricing; Model performance

${ }^{*}$ Corresponding author: Swansea University; Email: d.luo@swansea.ac.uk We thank Robert Van Ness and Richard Warr (the Editors) and an anonymous referee for their insightful comments and suggestions. Liu acknowledges financial support from the National Natural Science Foundation of China (No. 11171372). 


\section{Introduction}

Recent studies in asset pricing suggest that liquidity plays a significant role in investors' consumption and investment decision-making. ${ }^{1}$ In this paper, we extend the Epstein and Zin (1989, 1991) model with liquidity risk and show that consumption risk, market risk, and liquidity risk jointly determine expected returns. Specifically, using the liquidity risk factors of Pastor and Stambaugh (2003), Liu (2006), and Sadka (2006), we show that liquidity risk is significantly priced, suggesting that investors do care about the sensitivity of stock returns to market liquidity variations and demand high compensation for holding stocks with large exposure to liquidity risk. This evidence is consistent with recent literature that highlights the importance of liquidity in asset pricing (e.g., Chordia, Roll, and Subrahmanyam, 2000; Amihud, 2002; Pastor and Stambaugh, 2003; Acharya and Pedersen, 2005; Liu, 2006; Sadka, 2006; and Bekaert, Harvey, and Lundblad, 2007). However, prior studies largely examining whether liquidity risk is priced related to models other than consumption based such as the capital asset pricing model (CAPM) of Sharpe (1964) and Lintner (1965) and the Fama-French three-factor model (FF3FM). The main objective of this study is to assess the incremental contribution of liquidity risk to the performance of consumption-based pricing models.

Kan, Robotti, and Shanken (2013) argue that examining whether a factor makes an incremental contribution to a multi-factor model's goodness-of-fit is different from testing whether the factor is priced. ${ }^{2}$ They argue that, in a multi-factor model, it is important to test the significance of

\footnotetext{
${ }^{1}$ For instance, Liu (2010) demonstrates that liquidity risk originates from consumption and solvency constraints (Chien and Lustig (2010) and Pastor and Stambaugh (2003) also illustrate that liquidity concerns stem from solvency constraints). Parker and Julliard (2005) argue that liquidity risk is an imperative component ignored by consumption risk. Næs, Skjeltorp, and Ødegaard (2011) find significant relation between market liquidity and consumption growth.

${ }^{2}$ Cochrane (2005, Chapter 13) discusses a related issue in the stochastic discount factor (SDF) framework.
} 
covariance risk (the covariance between return and a risk factor). If the coefficient of the covariance is significantly different from zero, then the factor makes an incremental contribution to the model's overall explanatory power. Following Lewellen, Nagel, and Shanken (2010) and Kan, Robotti, and Shanken $(2013),{ }^{3}$ we perform both the ordinary least squares (OLS) and generalized least squares (GLS) regressions in our analysis. We find that the coefficient of the covariance between return and the liquidity risk factor is significant, indicating an improved model. Further, the liquidity-extended Epstein-Zin model explains up to $70 \%$ of the cross-sectional expected returns on the 25 Fama and French (1993) value-weighted size and book-to-market portfolios, a substantial improvement comparing to previous studies. ${ }^{4}$

Sadka (2006) show that incorporating liquidity risk into the traditional CAPM or the FamaFrench three-factor model accounts for a large proportion of cross-sectional return variations. It is, however, not clear whether the $R^{2}$ difference between competing models is significant. Applying the equality test of cross-sectional $R^{2}$ (Kan, Robotti, and Shanken (2013)), the null is rejected under both OLS and GLS estimates, indicating that the liquidity-extended model is more successful in explaining the cross-sectional expected returns than the traditional consumption-based capital asset pricing model (CCAPM) of Rubinstein (1976), Lucas (1978), and Breeden (1979), and the EpsteinZin (1989, 1991) model.

To further evaluate the model performance, we use Hansen and Jagannathan (1997) distance (HJ distance hereafter) as an alternative measure of a model's goodness-of-fit. We show that, compared to the traditional CCAPM and the Epstein-Zin model, our liquidity-extended Epstein-Zin model

\footnotetext{
${ }^{3}$ Lewellen, Nagel, and Shanken (2010) suggest that it is important to implement the GLS estimates besides OLS. Kan, Robotti, and Shanken (2013) argue that the OLS regression emphasizes more on the returns for a particular set of test portfolios, while the GLS may be potentially more interesting from an investment point of view.

${ }^{4}$ Lettau and Ludvigson (2001) show that the traditional CCAPM explains only $16 \%$ of the cross-sectional return variations based on quarterly data. Jagannathan and Wang (2007) find that the CCAPM has almost no explanatory power based on monthly data.
} 
generates a smaller HJ distance estimate. The null hypothesis that the squared HJ distances are equal is generally rejected based on the tests of Kan and Robotti (2009).

Lewellen, Nagel, and Shanken (2010) argue that, for pricing tests, it is important to include other sets of portfolios (e.g., industry portfolios) to break down the structure of size and book-tomarket portfolios. ${ }^{5}$ Recent studies also highlight the importance of the consumption-to-wealth ratio (Lettau and Ludvigson, 2001), long-run consumption risk (Parker and Julliard, 2005; and Malloy, Moskowitz, and Vissing-Jrgensen, 2009), and durable goods (Yogo, 2006; and Gomes, Kogan, and Yogo, 2009) in consumption-based asset pricing. In our robustness tests, we take these issues into account and find that both the liquidity risk premium and the coefficient of the covariance risk between return and liquidity risk factor are significant. Again, the extended Epstein-Zin model is more successful in explaining expected returns than the CCAPM and the Epstein-Zin model based on the equality tests of cross-sectional $R^{2}$ and the HJ distance.

We also examine the role of liquidity risk with non-consumption-based asset pricing models, namely, the CAPM, the FF3FM, and the Jagannathan and Wang (1996) conditional CAPM (JW). Consistent with our previous results, we find that, in general, liquidity risk is significantly priced, and the covariance risk of liquidity contributes significantly to the model's explanatory power.

One study that relates to ours is Márquez, Nieto, and Rubio (2014) in which the authors propose a liquidity-adjusted stochastic discount factor. However, our model differs from theirs. Márquez, Nieto, and Rubio (2014) assume a market illiquidity shock to consumption while we focus on liquidity costs and use liquidity risk factors developed by Pastor and Stambaugh (2003), Liu (2006), and Sadka (2006). Further, they show that liquidity risk is priced under ultimate consumption risk while our tests also take into account consumption growth, consumption-to-wealth ratio, long-run

\footnotetext{
${ }^{5}$ Recent studies of Savov (2011) and Kan, Robotti, and Shanken (2013) also incorporate industry portfolios. They use the 25 Fama-French size and book-to-market portfolios, plus industry portfolios, as test assets.
} 
consumption growth, and durable consumption growth. More importantly, our focus is on assessing the incremental contribution of liquidity risk to the model's performance, for which the test itself is new to the literature.

Overall, our paper highlights the role of liquidity in explaining cross-sectional expected returns under both theoretical and empirical approaches. By showing that liquidity is not only a priced factor but also contributes significantly to the model's explanatory power, we provide new evidence to the recent literature, which reveals the importance of liquidity risk in asset pricing (e.g., Chordia, Roll, and Subrahmanyam, 2000; Pastor and Stambaugh, 2003; Acharya and Pedersen, 2005; Liu, 2006; Sadka, 2006; and Bekaert, Harvey, and Lundblad, 2007). While these studies appear to make liquidity adjustment to the CAPM or the FF3FM, our paper focuses on the liquidity adjustment to the consumption-based pricing model and investigates the role of liquidity in model performance, an area that has attracted little attention in the literature.

We also apply recently developed econometrical techniques to conduct a wider range of asset pricing tests (e.g., model misspecification, covariance risk, OLS and GLS regressions, and equality tests of $R^{2}$ and HJ distance). Our study thus complements recent work on using new techniques in asset pricing tests (e.g., Kan and Robotti, 2009; Lewellen, Nagel, and Shanken, 2010; and Kan, Robotti, and Shanken, 2013). While these studies apply the new techniques to examine factors such as consumption growth, market, size, and book-to-market factors in pricing assets, we use these techniques to study the role of liquidity risk factor in explaining cross-sectional returns and in improving a model's goodness-of-fit. Further, unlike other advances of consumption-based asset pricing studies (e.g., Lettau and Ludvigson, 2001; Parker and Julliard, 2005; and Yogo, 2006), we highlight the importance of liquidity in understanding the empirically less successful performance of the CCAPM and the Esptein-Zin model in explaining cross-sectional expected returns. 


\section{The model}

By introducing liquidity costs to a standard representative-agent asset pricing model with Epstein-Zin preferences, we derive a liquidity risk-adjusted Epstein-Zin model:

$$
E\left[R_{i}-R_{f}\right]=\gamma_{c g} \beta_{i, c g}+\gamma_{m k t} \beta_{i, R_{W}}+\gamma_{l i q} \beta_{i, l i q}
$$

where $\beta_{i, c g}$ denotes the consumption beta, $\beta_{i, R_{W}}$ denotes the return to wealth beta, and $\beta_{i, l i q}$ denotes the liquidity beta; $\gamma_{c g}, \gamma_{m k t}$, and $\gamma_{l i q}$ are the prices of consumption risk, market risk, and liquidity risk. ${ }^{6}$ The liquidity-extended Epstein-Zin model is in line with recent studies supporting the important role of liquidity risk in asset pricing such as Pastor and Stambaugh (2003), Liu (2006), and Sadka (2006). These studies show that augmenting the traditional CAPM or the Fama-French three-factor model with a liquidity factor improves the performance of these models.

Incorporating liquidity risk into the consumption-based asset pricing model is consistent with economic intuition. When the economy is haunted by uncertainty that impacts consumption and squeezes liquidity, individual investors may unwillingly switch from their stocks to cash to smooth out consumption, and institutional investors may reluctantly exchange their holdings for cash to fulfill their obligations. Under these circumstances, stocks whose returns are less sensitive to market liquidity comfort investors from states of low consumption. On the contrary, stocks with high liquidity risk impair investors' abilities to cushion the deterioration in consumption. As a result, investors require high compensation for holding high liquidity-risk stocks.

\footnotetext{
${ }^{6}$ Based on the wealth dynamic of Lynch and Tan (2011), Appendix A shows the derivation of Eq. (1). Appendix B shows the alternative derivation of Eq. (1) with the theoretical framework of Yogo (2006).
} 


\section{Data}

The literature proposes a number of liquidity measures together with several liquidity risk factors. To empirically test the liquidity-extended Epstein-Zin model, we use three alternative proxies for the liquidity risk factor: (1) the aggregate liquidity innovation of Pastor and Stambaugh (2003), where liquidity is measured as the price reversal caused by the temporary price impact of trading volume; (2) Liu's (2006) mimicking liquidity factor constructed based on the trading discontinuity measure of liquidity, the standardized turnover-adjusted number of zero daily trading volumes; and (3) Sadka's (2006) aggregate liquidity innovation constructed based on the variable component of price impact. $^{7}$

We measure the aggregate consumption growth as the percentage change from preceding period (one month) of per capita real personal consumption expenditures on nondurable goods and services. We obtain consumption expenditures, population numbers, and price deflator series from the National Income and Product Accounts (NIPA). ${ }^{8}$ We use the "end of period" time convention to match the aggregate consumption growth to stock returns. ${ }^{9}$ For robustness tests, we also use the consumption-to-wealth ratio (cay) of Lettau and Ludvigson (2001), consumption growth of nondurable goods over a long horizon of 36 months (cg36) of Parker and Julliard (2005), and durable consumption growth $(c g d)$ of Yogo (2006). ${ }^{10}$ Savov (2011) provides detailed discussions about the conceptual and methodological issues of consumption data.

\footnotetext{
${ }^{7}$ We obtain the monthly values of the Pastor and Stambaugh (2003) factor and the Sadka factor from WRDS.

${ }^{8}$ The NIPA website is http://www.bea.gov/iTable.

${ }^{9}$ Under the "end of period" timing convention, we assume that the consumption data measure consumption at the end of the month. An alternative convention is the "beginning of period" as in Campbell (2003).

${ }^{10}$ From Sydney Ludvigson's website of http://www.econ.nyu.edu/user/ludvigsons/, we obtain the consumption-to-wealth ratio. Since cay data are quarterly, we linearly interpolate the quarterly values to the monthly values following VissingJørgensen and Attanasio (2003). We calculate the consumption growth over 36 months by $c g 36=\frac{C_{t+36}}{C_{t}}-1$, where $c g$ denotes the consumption growth of nondurable goods. The consumption data of nondurable and durable goods are from NIPA.
} 
Our main test assets are the 25 Fama-French value-weighted size and book-to-market portfolios. We also expand the 25 Fama-French portfolios with five value-weighted industries in the robustness tests, following Lewellen, Nagel, and Shanken (2010). To empirically test the liquidity-extended Epstein-Zin model, we use the excess return of the value-weighted NYSE/Amex/Nasdaq/ARCA index to proxy for the return to wealth factor $\left(R_{W}\right)$, following Epstein and Zin (1991) and Yogo (2006). We use the one-month treasury bill rate as the risk-free rate. ${ }^{11}$ Our sample period varies depending on the availability of the liquidity risk factor of interest. The Pastor and Stambaugh (2003) liquidity factor is available from 1962 to 2010. For the Liu (2006) liquidity risk factor, our test period is 1959-2010 since the monthly consumption data become available in 1959. The Sadka (2006) liquidity factor is available from 1983 to 2010.

Table 1 provides descriptive statistics for the main variables. Consumption growth $(c g)$ is positively correlated with the market factor $(m k t)$. However, $c g$ is virtually uncorrelated with all three liquidity risk factors. In addition, the correlations between the liquidity risk factors are low, indicating that they capture different information and thus are useful for testing the robustness of the liquidity-extended Epstein-Zin model.

Figure 1 shows the time-series pattern of the aggregate liquidity innovation of Pastor and Stambaugh (2003) from 1962 to 2010 (Panel A), Liu's (2006) mimicking liquidity risk factor from 1959 to 2010 (Panel B), and Sadka's (2006) aggregate liquidity innovation based on the variable component of price impact from 1983 to 2010 (Panel C). These risk factor series identify several shocks in market liquidity. For example, they all coincide with the 1998 Russian debt crisis and the collapse of the US hedge fund Long Term Capital Management.

\footnotetext{
${ }^{11}$ We obtain the 25 Fama-French portfolio returns, excess market returns, and one-month T-Bill rates from French's website: http://mba.tuck.dartmouth.edu/pages/faculty/ken.french/.
} 


\section{Cross-sectional regressions}

\subsection{Factor loadings of the liquidity-extended Esptein-Zin model}

We first estimate and examine the loadings on the consumption, market, and liquidity factors. The estimation of factor loadings corresponds to the first-step of the Fama-MacBech (1973) procedure. In particular, for each of the 25 Fama-French size and book-to-market portfolios, we estimate the loadings from a single multiple time-series regression:

$$
R_{i}=\alpha_{i}+\beta_{c g, i} f_{c g}+\beta_{m k t, i} f_{m k t}+\beta_{l i q, i} f_{l i q}+e_{i},
$$

where $f_{c g}$ denotes the consumption growth on nondurable goods and services, $f_{m k t}$ denotes the excess returns of the market portfolio proxied by the value-weighted NYSE/Amex/Nasdaq/ARCA index, and $f_{l i q}$ denotes the liquidity factor.

Table 2 shows that liquidity betas $\left(\beta_{l i q, i}\right)$ are related to size and book-to-market ratios. Within each book-to-market quintile, liquidity betas are lower for large stocks and higher for small stocks. Similarly, liquidity betas increase with book-to-market ratio for a given size quintile. In untabulated results that are available upon request, we find that consumption betas are related to firm size: small (large) stocks have high (low) consumption betas. Consumption betas exhibit, however, a counter-intuitive pattern in book-to-market ratio for a given size quintile, which is consistent with Yogo (2006). Similarly, loadings on the market factor decrease with market caps, but increase with book-to-market ratios, in line with Petkova (2006).

\subsection{Risk premium}

This subsection investigates whether liquidity risk is priced by running the following crosssectional regression: 


$$
R_{i, t}=\gamma_{0}+\gamma_{c g} \beta_{i, c g}+\gamma_{m k t} \beta_{i, m k t}+\gamma_{l i q} \beta_{i, l i q}+e_{i, t}
$$

where $R_{i, t}$ is the month- $t$ rate of return of portfolio $i$. The consumption beta $\left(\beta_{i, c g}\right)$, market beta $\left(\beta_{i, m k t}\right)$, and liquidity beta $\left(\beta_{i, l i q}\right)$ are estimated from the multiple time-series regression (2) for each testing portfolio over the entire sample period. ${ }^{12}$ We estimate model parameters $(\gamma \mathrm{s})$ using the 25 Fama-French value-weighted size and book-to-market portfolios.

Table 3 reports the estimated risk premium $(\gamma)$ under both the ordinary least squares (OLS) and generalized least squares (GLS) regressions, recommended by Lewellen, Nagel, and Shanken (2010) and Kan, Robotti, and Shanken (2013). We use alternative $t$-ratios to test the significance of $\gamma$ : the FM $t$-ratio of Fama and MacBeth (1973), the SH $t$-ratio of Shanken (1992) with errors-in-variables adjustment, the JW $t$-ratio of Jagannathan and Wang (1996), and the KRS $t$-ratio of Kan, Robotti, and Shanken (2013) under potentially misspecified models. ${ }^{13}$

For the OLS estimates, we find that the liquidity risk $\left(\beta_{l i q}\right)$ is positively priced in the crosssectional analysis, consistent with the model's prediction. The $\gamma$ estimate is significantly different from zero with all $t$-ratios at the $5 \%$ level, except for the Sadka (2006) liquidity factor. ${ }^{14}$ For the GLS estimates, the coefficient on $\beta_{l i q, i}$ is significantly positive, regardless of the liquidity factors and $t$-ratios used. The evidence suggests that investors do care about liquidity risk and require a high compensation for bearing it. In contrast, for both OLS and GLS estimates, the coefficient on consumption risk $\left(\beta_{c g}\right)$ is generally positive but insignificant at the conventional level. This finding is consistent with previous studies (e.g., Lettau and Ludvigson, 2001; and Lustig and Nieuwerburgh,

\footnotetext{
${ }^{12}$ We estimate the consumption, market, and liquidity betas over the entire sample period as in Lettau and Ludvigson (2001), Acharya and Pedersen (2005), and Sadka (2006), throughout the paper.

${ }^{13}$ Kan and Robotti (2008, 2009) and Balduzzi and Robotti (2010) also highlight the potential model misspecification problem in the statistical inference of the estimated risk premium.

${ }^{14}$ The coefficient on the liquidity beta estimated with the Sadka (2006) liquidity factor is significant at the $5 \%$ level according to the FM $t$-ratio.
} 
2005) that the CCAPM does a poor job in explaining cross-sectional stock returns. Also, consistent with early studies such as Fama and French (1992), market beta lacks power in predicting returns. In fact, market factor loading is even negatively related to returns when the Pastor-Stambaugh factor loading or the Sadka factor loading is involved in the cross-section regressions. ${ }^{15}$ We also conduct the Wald test of joint significance of the parameters for the liquidity-extended Epstein-Zin model. The null hypothesis that the parameters are jointly zero is rejected at the conventional level.

\subsection{Price of covariance risk}

Kan, Robotti, and Shanken (2013) argue that the price of covariance risk is related to the rise of explanatory power to the cross-sectional return variations in a multi-factor model. It is, therefore, important to test whether the coefficient of covariance risk relating to a particular factor is significantly different from zero. Kan, Robotti, and Shanken (2013) provide detailed mathematical derivation for the role of covariance risk in their Internet Appendix A. We provide a simple illustration using the original two-factor Epstein-Zin model based on the Internet Appendix C of Kan, Robotti, and Shanken (2013). Let $\gamma=\left[\gamma_{0}, \gamma_{c g}, \gamma_{m k t}\right]^{\prime}$, where $\gamma_{0}$ is the zero-beta rate, $\gamma_{c g}$ is the risk premium for consumption growth $(c g)$, and $\gamma_{m k t}$ is the risk premium for excess market return (mkt). Similarly, let $\lambda=\left[\lambda_{0}, \lambda_{c g}, \lambda_{m k t}\right]^{\prime}$, where $\lambda_{0}$ is the zero-beta rate, $\lambda_{c g}$ is the price of covariance risk for consumption growth $(c g)$, and $\lambda_{m k t}$ is the price of covariance risk for excess market return $(m k t)$. Suppose $c g$ and $m k t$ have the following values:

$$
V_{f}=\left[\begin{array}{cc}
0.03 & -0.02 \\
-0.02 & 0.03
\end{array}\right]
$$

\footnotetext{
${ }^{15}$ Jagannathan and Wang (1996), Lettau and Ludvigson (2001), and Petkova (2006) report the negative estimates for the market risk premium.
} 
Suppose there are four assets whose expected returns are $R=[0.02,0.03,0.04,0.05]^{\prime}$. Their covariance with $c g$ and $m k t$ are

$$
V_{f R}=\left[\begin{array}{cccc}
0.01 & 0.02 & 0.03 & 0.04 \\
0.03 & 0.05 & 0.02 & 0.01
\end{array}\right]
$$

In this setting, the covariances between the four assets and the first factor alone can fully account for the returns of the four assets, since the relation between $R$ and the first row of $V_{f R}$ is linear. On the contrary, when we compute the betas with respect to the consumption and market factors, we can have

$$
\beta=\left[\begin{array}{ll}
1.80 & 2.20 \\
3.20 & 3.80 \\
2.60 & 2.40 \\
2.80 & 2.20
\end{array}\right] .
$$

Further, we can obtain $\gamma_{0}=0.01, \gamma_{c g}=0.03$, and $\gamma_{m k t}=-0.02$. Note that $\gamma_{m k t}$ is nonzero even though the market factor is irrelevant. This suggests that, when the CCAPM is correctly specified, it does not necessarily mean that the market beta in the Epstein-Zin model should not be priced.

When we assume that the expected returns are $R=[0.1,0.17,0.14,0.15]^{\prime}$, the covariances with respect to the first factor alone cannot fully explain the expected returns. However, the relation between $R$ and the first column of $\beta$ is linear. Further, we can obtain $\gamma_{0}=0.01, \gamma_{c g}=0.05$, and $\gamma_{m k t}=0$. Note that $\gamma_{m k t}$ is zero even though the market factor is necessary in explaining the expected returns. The above numerical example highlights the importance of covariance risk and explains why it adds more explanatory power to the asset pricing models. 
Following Kan, Robotti, and Shanken (2013), we run the following cross-sectional regression:

$$
R_{i, t}=\lambda_{0}+\lambda_{c g} \operatorname{Cov}\left(R_{i}, c g\right)+\lambda_{m k t} \operatorname{Cov}\left(R_{i}, m k t\right)+\lambda_{l i q} \operatorname{Cov}\left(R_{i}, l i q\right)+e_{i, t},
$$

where $\operatorname{Cov}\left(R_{i}, \mathrm{cg}\right)$ denotes the covariance of returns and consumption growth, $\operatorname{Cov}\left(R_{i}, m k t\right)$ denotes the covariance of returns and excess market returns, and $\operatorname{Cov}\left(R_{i}, l i q\right)$ denotes the covariance of returns and the liquidity factor. These covariances are estimated for each testing portfolio over the entire sample period.

Table 4 reports the parameter $(\lambda)$ estimates of the OLS and GLS regressions of portfolio returns on the three covariances. The results are similar to those presented in Table 3. For the OLS estimates, the coefficient of the covariance between return and market liquidity is significantly positive at the $5 \%$ level for all $t$-ratios except for the Sadka (2006) liquidity factor. ${ }^{16}$ Under the GLS estimates, $\lambda_{\text {liq }}$ is significantly positive, regardless of the liquidity factors and $t$-ratios used. Overall, Table 4 shows that, according to Kan, Robotti, and Shanken (2013), the liquidity adjustment adds significant explanatory power to the model.

\subsection{Model performance}

In this sub-section, we compare the performance of the liquidity-extended Epstein-Zin model with other consumption pricing models. Following Kandel and Stambaugh (1995), our comparison first uses the sample cross-sectional $R^{2}$, which is given by:

$$
R^{2}=1-\frac{{\overline{\epsilon_{w}}}^{\prime} W \overline{\epsilon_{w}}}{\overline{\bar{\epsilon}_{0}^{\prime}} W \overline{\epsilon_{0}}}
$$

where $\overline{\epsilon_{0}}$ is the deviations of mean sample returns from their cross-sectional average and $\overline{\epsilon_{w}}{ }^{\prime} W \overline{\epsilon_{w}}$ is the aggregate pricing-error measure. Table 5 reports the sample cross-sectional $R^{2}$. Specifi-

\footnotetext{
${ }^{16}$ The coefficient on the covariance of portfolio returns with the Sadka (2006) liquidity factor is significant at the $5 \%$ level according to the FM $t$-ratio and at the $10 \%$ level according to the $\mathrm{SH} t$-ratio.
} 
cally, for the 25 Fama-French value-weighted size and book-to-market portfolios, the fraction of cross-sectional return variations explained by our liquidity-extended Epstein-Zin model is $59.1 \%$, $67.2 \%$, and $69.0 \%(27.3 \%, 23.9 \%$, and $47.5 \%)$ under the OLS (GLS) regressions, using the Pastor and Stambaugh (2003), Liu (2006), and Sadka (2006) liquidity factors, respectively. In contrast, the traditional CCAPM and the Epstein-Zin model explain a much smaller proportion of return variations. For example, the corresponding figures relative to the original Epstein-Zin model are $29.8 \%, 37.5 \%$, and $51.7 \%(10.9 \%, 14.0 \%$, and $23.8 \%)$ under the OLS (GLS) regressions.

Kan, Robotti, and Shanken (2013) argue that it is important to test whether the seemingly better performance of one model over another is statistically significant. We thus test whether the differences of the cross-sectional $R^{2}$ between our model and the traditional CCAPM or the EpsteinZin model are statistically significant. Following Kan, Robotti, and Shanken (2013), we estimate the $p$ value under the null hypothesis that the cross-sectional $R^{2} \mathrm{~s}$ of two competing models are equal.

Table 5 shows that, under the OLS (GLS) estimates, our model offers $59.0 \%$ (23.7\%) to $67.2 \%$ (47.2\%) additional explanatory power compared to the traditional CCAPM. Further, the null hypothesis of the equality of cross-sectional $R^{2} \mathrm{~s}$ is rejected at the $5 \%$ level, regardless of the estimation methods and liquidity factors used. Similarly, the liquidity-extended Epstein-Zin model also significantly explains a larger fraction of return variations than the Epstein-Zin model, expect for the Sadka (2006) liquidity factor under the OLS estimates.

As an alternative to the cross-sectional $R^{2}$ test, the HJ distance of Hansen and Jagannathan (1997) also evaluates a model's power in explaining asset prices. Accordingly, our second comparison relies on the HJ distance. Smaller HJ distances indicate smaller pricing errors. Similar to the argument about tests of equality of cross-sectional $R^{2}$, Kan and Robotti (2009) develop tests of 
equality of squared HJ distances to examine whether a smaller (bigger) HJ distance of one model over another is statistically significant. Following their work, we conduct tests of equality of squared HJ distances, which are based on their Proposition 2 for nested models and Proposition 6 for nonnested models.

For tests of equality of squared HJ distances of two nested models, Kan and Robotti (2009) show that the asymptotic distribution of the sample squared HJ distances is related to the asymptotic variance of estimated coefficients on risk factor loadings. The variance of the estimated coefficients on factor loadings is adjusted by potential model misspecification. For example, the liquidityextended model nests the original Epstein-Zin model. The extra factor is the liquidity risk factor. Therefore, the asymptotic distribution for the test of equality of squared HJ distances is associated with the asymptotic variance of estimated coefficients on liquidity risk. The variance of the estimated coefficients on liquidity risk is adjusted by potential model misspecification.

For tests of equality of squared HJ distances of two nonnested models, we follow Kan and Robotti (2009) by assuming that the two models have equal stochastic discount factor (SDF) and are both misspecified. Under these assumptions, the asymptotic distribution of the sample squared HJ distances is asymptotically normally distributed. The $p$ value of the test statistic associated with the hypothesis that the squared HJ distances of two competing models are equal can be computed accordingly.

Table 5 presents the results of the tests of equality of squared HJ distances between alternative models. Similar to the cross-sectional $R^{2}$ tests, the liquidity-extended Epstein-Zin model produces smaller HJ distance than the CCAPM and the Epstein-Zin model. The null hypothesis that the squared HJ distances of two competing models are equal is rejected at the $5 \%$ level under both Liu (2006) and Sadka (2006) liquidity factors. 


\subsection{Fitted versus realized returns}

Figure 2 plots the realized average portfolio returns and the fitted portfolio returns. With the traditional CCAPM, the fitted expected returns are calculated as $E[R]=\gamma_{0}+\gamma_{c g} \beta_{c g}$. Based on the Epstein-Zin model, the fitted expected return is $E[R]=\gamma_{0}+\gamma_{c g} \beta_{c g}+\gamma_{m k t} \beta_{m k t}$. The fitted expected returns under the liquidity-extended Epstein-Zin model are calculated as $E[R]=$ $\gamma_{0}+\gamma_{c g} \beta_{c g}+\gamma_{m k t} \beta_{m k t}+\gamma_{l i q} \beta_{l i q}$

Each two-digit number in Figure 2 indicates one portfolio. The first digit denotes the size quintile ( 1 representing the smallest and 5 the largest), and the second denotes the book-to-market quintile ( 1 representing the lowest and 5 the highest). The vertical distance of these points to the 45 degree line represents the pricing errors. Figure 2 shows that overall the pricing errors associated with the liquidity-extended Epstein-Zin model are smaller than those associated with either the traditional CCAPM or the original Epstein-Zin model. Specifically, the CCAPM or the EpsteinZin model has difficulties in explaining the expected returns of book-to-market portfolios for a given size quintile. For instance, performances of the small growth portfolio (portfolio 11) and the small value portfolio (portfolio 15) are poorly described by the CCAPM and the Epstein-Zin model. In contrast, there is substantial improvement in nearly all the size and book-to-market portfolios for the liquidity-extended Epstein-Zin model. It especially reduces the pricing error of small value portfolios.

\section{Robustness tests}

In this section, we first test the robustness of our results by examining the estimated risk premium and the price of covariance risk under various adjustments and by adding industry portfolios 
to the 25 Fama-French test portfolios. We then test the robustness of the model performance under these new settings.

\subsection{Robustness on risk premium and price of covariance risk}

Lettau and Ludvigson (2001) show that the traditional CCAPM conditional on the consumptionto-wealth ratio (cay) explains the expected return variations as well as the Fama-French three-factor model does. We embed cay and the product of $c g$ and $c a y(c g \cdot c a y)$ into the liquidity-extended Epstein-Zin model to test the robustness of our results. Specifically, we run the following two Fama-MacBeth cross-sectional regressions:

$$
\begin{gathered}
R_{i, t}=\gamma_{0}+\gamma_{c g} \beta_{i, c g}+\gamma_{c a y} \beta_{i, c a y}+\gamma_{c g \cdot c a y} \beta_{i, c g \cdot c a y}+\gamma_{m k t} \beta_{i, m k t}+\gamma_{l i q} \beta_{i, l i q}+e_{i, t}, \\
R_{i, t}=\lambda_{0}+\lambda_{c g} \operatorname{Cov}\left(R_{i}, c g\right)+\lambda_{c a y} \operatorname{Cov}\left(R_{i}, \operatorname{cay}\right)+\lambda_{c g \cdot c a y} \operatorname{Cov}\left(R_{i}, c g \cdot c a y\right) \\
+\lambda_{m k t} \operatorname{Cov}\left(R_{i}, m k t\right)+\lambda_{l i q} \operatorname{Cov}\left(R_{i}, l i q\right)+e_{i, t} .
\end{gathered}
$$

Panel A of Table 6 shows that, after controlling for cay, the estimated risk premium and the price of covariance risk for the liquidity factors remain significantly positive at the $5 \%$ level, except for the Sadka (2006) liquidity factor under the OLS estimates. ${ }^{17}$

Bansal and Yaron (2004), Parker and Julliard (2005), Da (2009), Malloy, Moskowitz, and Vissing-Jørgensen (2009), and Favilukis and Lin (2013) highlight the importance of long-run consumption risk in explaining the cross-sectional variations of expected returns. Following Parker and Julliard (2005), we measure consumption risk by using the consumption growth of nondurable goods over 36 months (cg36) to test the liquidity-extended Epstein-Zin model. Specifically, we run the following two cross-sectional regressions:

\footnotetext{
${ }^{17}$ The coefficient on the liquidity beta based on the Sadka (2006) liquidity factor is significant at the $5 \%$ level according to the FM $t$-ratio under the OLS estimates. The coefficient on the covariance between portfolio return and the Sadka (2006) liquidity factor is significant at the $5 \%(10 \%)$ level according to the FM (SH) $t$-ratio under the OLS estimates.
} 


$$
\begin{gathered}
R_{i, t}=\gamma_{0}+\gamma_{c g 36} \beta_{i, c g 36}+\gamma_{m k t} \beta_{i, m k t}+\gamma_{l i q} \beta_{i, l i q}+e_{i, t}, \\
R_{i, t}=\lambda_{0}+\lambda_{c g 36} \operatorname{Cov}\left(R_{i}, c g 36\right)+\lambda_{m k t} \operatorname{Cov}\left(R_{i}, m k t\right)+\lambda_{l i q} \operatorname{Cov}\left(R_{i}, l i q\right)+e_{i, t} .
\end{gathered}
$$

Table 6, Panel B, shows that, in general, liquidity risk is significantly priced and the covariance risk of liquidity contributes significantly to the model's explanatory power.

Recent studies point out that, when utility is nonseparable in nondurable and durable consumption, the durable goods play an important role in determining expected returns (Yogo, 2006; and Gomes, Kogan, and Yogo, 2009). Following Yogo (2006), we incorporate the durable consumption growth $(c g d)$ into our model and run the following two cross-sectional regressions:

$$
\begin{gathered}
R_{i, t}=\gamma_{0}+\gamma_{c g} \beta_{i, c g}+\gamma_{c g d} \beta_{i, c g d}+\gamma_{m k t} \beta_{i, m k t}+\gamma_{l i q} \beta_{i, l i q}+e_{i, t}, \\
R_{i, t}=\lambda_{0}+\lambda_{c g} \operatorname{Cov}\left(R_{i}, c g\right)+\lambda_{c g d} \operatorname{Cov}\left(R_{i}, c g d\right)+\lambda_{m k t} \operatorname{Cov}\left(R_{i}, m k t\right)+\lambda_{l i q} \operatorname{Cov}\left(R_{i}, l i q\right)+e_{i, t} .
\end{gathered}
$$

Table 6, Panel C, shows that, for the Pastor and Stambaugh (2003) liquidity factor, the coefficients of the liquidity risk $\left(\gamma_{l i q}\right)$ and the covariance risk related to liquidity $\left(\lambda_{l i q}\right)$ are statistically significant with the FM $t$-ratio (FM, SH, and JW $t$-ratios) under the OLS (GLS) estimates. For the Liu (2006) factor, $\gamma_{l i q}$ significantly differs from zero at the $1 \%$ level. For the Sadka (2006) factor, $\gamma_{l i q}$ and $\lambda_{l i q}$ are significantly different from zero at the $5 \%$ level, except for the KRS $t$-ratio under the OLS estimates.

Lewellen, Nagel, and Shanken (2010) argue that the tight factor structure of size and book-tomarket portfolios tends to be less powerful in rejecting misspecified asset pricing models and results in high $R^{2}$ in cross-sectional tests. They advocate that asset pricing tests should incorporate other 
sets of portfolios (e.g., industry portfolios) to disintegrate the structure of size and book-to-market portfolios. To address this concern, we expand the 25 Fama-French value-weighted size and bookto-market portfolios with five value-weighted industry portfolios of Gomes, Kogan, and Yogo (2009). Table 6, Panel D, reports the results for the 30 test portfolios. Results are similar to previous ones, i.e., the estimated liquidity risk premium and the price of covariance risk relating to liquidity are, in general, significant under the 30 test portfolios.

\subsection{Robustness on cross-sectional $R^{2}$ and $H J$ distance}

Based on the above adjustments, we conduct further robustness tests on the model's goodnessof-fit. Specifically, following Lettau and Ludvigson (2001) and Yogo (2006), we incorporate cay (and $c g \cdot c a y)$ and $c g d$ into the CCAPM, the Epstein-Zin model, and the liquidity-extended Epstein-Zin model to take into account consumption-to-wealth ratio and durable goods. ${ }^{18}$ We follow Parker and Julliard (2005) and measure consumption growth over a horizon of 36 months (cg36) to test the above models. We use the 25 Fama-French size and book-to-market portfolios plus five industry portfolios of Gomes, Kogan, and Yogo (2009) as the alternative test portfolios to examine the performance of these models.

Panels $\mathrm{A}$ and $\mathrm{B}$ of Table 7 report the results on the differences of cross-sectional $R^{2}$ and HJ distance by comparing the liquidity-extended Epstein-Zin model with the traditional CCAPM and the Epstein-Zin model. It shows that the liquidity-extended model, in general, significantly outperforms the CCAPM and the Epstein-Zin model after adjusting for consumption-to-wealth ratio, long-run consumption risk, durable consumption growth, and industry portfolios.

\footnotetext{
${ }^{18}$ Incorporating cay (and $c g \cdot c a y$ ) and $c g d$ into the CCAPM and the Epstein-Zin model yields a three-factor (two-factor) model and a four-factor (three-factor) model.
} 


\subsection{Robustness with other asset pricing models}

To further test the role of liquidity factor, we also examine the marginal explanation power of liquidity risk relative to other pricing models:

$$
\begin{gathered}
E\left(R_{i}-R_{f}\right)=\gamma_{m k t} \beta_{i, m k t}, \\
E\left(R_{i}-R_{f}\right)=\gamma_{m k t} \beta_{i, m k t}+\gamma_{s m b} \beta_{i, s m b}+\gamma_{h m l} \beta_{i, h m l}, \\
E\left(R_{i}-R_{f}\right)=\gamma_{m k t} \beta_{i, m k t}+\gamma_{l a b} \beta_{i, l a b}+\gamma_{p r e m} \beta_{i, p r e m} .
\end{gathered}
$$

Eq. (15) is the CAPM, Eq. (16) is the Fama-French three-factor model (FF3FM), and Eq. (17) is the Jagannathan and Wang (1996) (JW) model. The notation $\gamma_{m k t}$ is the expected value of the market factor. In Eq. (16), $\gamma_{s m b}$ is the expected value of the size factor, and $\gamma_{h m l}$ is the expected value of the book-to-market factor. In Eq. (17), $\gamma_{l a b}$ is the expected growth rate in per capita labor income $(L)$ defined as the difference between total personal income and dividend payments, divided by the total population from the National Income and Product Accounts (NIPA), and $\gamma_{\text {prem }}$ is the lagged yield spread between Baa- and Aaa-rated corporate bonds from the Board of Governors of the Federal Reserve System. ${ }^{19}$ Following Jagannathan and Wang (1996), the growth rate in per

capita labor income $(L)$ is proxied by a two-month moving average of $\frac{L_{t-1}+L_{t-2}}{L_{t-2}+L_{t-3}}-1$ to mitigate the influence of measurement errors.

We incorporate the liquidity factor into the above three models and then evaluate whether liquidity risk is priced and whether the liquidity factor contributes to the increase of cross-sectional $R^{2}$. Table 8 shows that, in general, liquidity risk is significantly priced and the covariance risk of liquidity contributes significantly to the model's explanatory power. We also examine whether

\footnotetext{
${ }^{19}$ http://research.stlouisfed.org/fred2/
} 
these liquidity-extended Epstein-Zin models outperform the original models. Table 9 shows that extensions to the CAPM, the FF3FM, and the JW model perform better than the original models.

\section{Conclusion}

Liquidity costs, which are generally related to transaction costs, thin or infrequent trading, and the impact of trading on price, affect investors' investment return and consumption. Recently, a series of papers (Pastor and Stambaugh, 2003; Liu, 2006; and Sadka, 2006) highlight the importance of liquidity in asset pricing. While existing studies appear to make adjustment to the CAPM or the Fama-French three-factor model with liquidity risk and show that models with liquidity adjustment reveal significantly increased explanatory power, few studies incorporate liquidity risk into consumption-based pricing models. In this paper, we develop a liquidity-extended Epstein-Zin model under the setting that after taking into account liquidity costs, individuals maximize their life-time utility of consumption. Our model reveals that, in addition to the consumption and market risks, expected stock return is also determined by liquidity risk.

Applying a number of newly developed procedures in testing asset pricing models, we empirically evaluate our three-beta pricing model against the traditional CCAPM and the Epstein-Zin two-beta model. We find that the liquidity risk is fairly priced, and the liquidity factor makes a significant contribution to explain cross-sectional expected returns. In contrast with the significant pricing power of liquidity risk, consumption risk and market risk generally display insignificant return predictability.

In terms of both the cross-sectional $R^{2}$ and the Hansen and Jagannathan (1997) distance, the results show that our model performs better than the traditional CCAPM and the Epstein-Zin model based on the equality tests of the cross-sectional $R^{2}$ (Kan, Robotti, and Shanken, 2013) 
and the HJ distance (Kan and Robotti, 2009). Thus, our results not only support the extension of liquidity risk to asset pricing, but the extension also helps to explain why the empirical performance of the CCAPM and the Epstein-Zin model is less successful. 


\section{References}

Acharya, V. V. and L. H. Pedersen, 2005. Asset pricing with liquidity risk, Journal of Financial Economics $77,375-410$.

Amihud, Y., 2002. Illiquidity and stock returns: Cross-section and time-series effects, Journal of Financial Markets 5, 31-56.

Amihud, Y. and H. Mendelson, 1986. Asset pricing and the bid-ask spread, Journal of Financial Economics $17,223-249$.

Balduzzi, P. and C. Robotti, 2010. Asset pricing models and economic risk premia: A decomposition, Journal of Empirical Finance 17, 54-80.

Bansal, R. and A. Yaron, 2004. Risks for the long run: A potential resolution of asset pricing puzzles, Journal of Finance 59, 1481-1509.

Bekaert, G., C. R. Harvey, and C. Lundblad, 2007. Liquidity and expected returns: Lessons from emerging markets, Review of Financial Studies 20, 1783-1831.

Breeden, D. T., 1979. An intertemporal asset pricing model with stochastic consumption and investment opportunities, Journal of Financial Economics 7, 265-296.

Campbell, J. Y., 2003. Consumption-based asset pricing, Handbook of the Economics of Finance Vol. 1B, Chapter 13, pp. 801-885 (Elsevier: Amsterdam).

Chien, Y. and H. Lustig, 2010. The market price of aggregate risk and the wealth distribution. Review of Financial Studies 23, 1596-1650.

Chordia, T., R. Roll, and A. Subrahmanyam, 2000. Commonality in liquidity, Journal of Financial Economics 56, 3-28.

Cochrane, J. H., 2005. Asset pricing, revised edition, Princeton University Press.

Da, Z., 2009. Cash flow, consumption risk, and the cross-section of stock returns, Journal of Finance 64, 923-956.

Epstein, L. G. and S. E. Zin, 1989. Substitution, risk aversion, and the temporal behavior of consumption and asset returns: A theoretical framework, Econometrica 57, 937-969.

Epstein, L. G. and S. E. Zin, 1991. Substitution, risk aversion, and the temporal behavior of consumption and asset returns: An empirical investigation, Journal of Political Economy 99, 263-286.

Fama, E. F. and K. R. French, 1992. The cross-section of expected stock returns, Journal of Finance 47, 427-465.

Fama, E. F. and K. R. French, 1993. Common risk factors in the returns on stocks and bonds, Journal of Financial Economics 33, 3-56.

Fama, E. F. and J. D. MacBeth, 1973. Risk, return, and equilibrium: Empirical tests, Journal of Political Economy 81, 607-636.

Favilukis, J. and X. Lin, 2013. Long run productivity risk and aggregate investment, Journal of Monetary Economics 60, 737-751.

Gomes, J. F., L. Kogan, and M. Yogo, 2009. Durability of output and expected stock returns, Journal of Political Economy 117, 941-986. 
Gu, L. and D. Huang, 2013. Consumption, money, intratemporal subsitution, and cross-sectional asset returns, Journal of Financial Research 36, 115-146.

Hansen, L. P. and R. Jagannathan, 1997. Assessing specification errors in stochastic discount factor models, Journal of Finance 52, 557-590.

Hasbrouck, J. and D. J. Seppi, 2001. Common factors in prices, order flows, and liquidity. Journal of Financial Economics 59, 383-411.

Jacoby, G., D. J. Fowler, and A. A. Gottesman, 2000. The capital asset pricing model and the liquidity effect: A theoretical approach. Journal of Financial Markets 3, 69-81.

Jagannathan, R. and Y. Wang, 2007. Lazy investors, discretionary consumption, and the cross-section of stock returns, Journal of Finance 62, 1623-1661.

Jagannathan, R. and Z. Wang, 1996. The conditional CAPM and the cross-section of expected returns, Journal of Finance 51, 353.

Jang, B. G., H. K. Koo, H. Liu, and M. Loewenstein, 2007. Liquidity premia and transaction costs, Journal of Finance 62, 2329-2366.

Kan, R. and C. Robotti, 2008. Specification tests of asset pricing models using excess returns, Journal of Empirical Finance 15, 816-838.

Kan, R. and C. Robotti, 2009. Model comparison using the Hansen-Jagannathan distance, Review of Financial Studies 22, 3449-3490.

Kan, R., C. Robotti, and J. Shanken, 2013. Pricing model performance and the two-pass cross-sectional regression methodology, Journal of Finance 68, 2617-2649.

Kandel, S. and R. F. Stambaugh, 1995. Portfolio inefficiency and the cross-section of expected returns, Journal of Finance 50, 157-184.

Lettau, M. and S. Ludvigson, 2001. Resurrecting the (C)CAPM: A cross-sectional test when risk premia are time-varying, Journal of Political Economy 109, 1238-1287.

Lewellen, J., S. Nagel, and J. Shanken, 2010. A skeptical appraisal of asset pricing tests, Journal of Financial Economics 96, 175-194.

Lintner, J., 1965. Security prices, risk, and maximal gains from diversification, Journal of Finance 20, 587-615.

Lioui, A. and P. Maio, 2014. Interest rate risk and the cross section of stock returns, Journal of Financial and Quantitative Analysis 49, 483-511.

Liu, W., 2006. A liquidity-augmented capital asset pricing model, Journal of Financial Economics 82, 631-671.

Liu, W., 2010. Liquidity risk and asset pricing: Evidence from daily data, 1926-2009, Working Paper, University of Nottingham.

Lo, A. W., H. MacKinlay, and J. Wang, 2004. Asset prices and trading volume under fixed transactions costs, Journal of Political Economy 112, 1054-1090.

Lucas Jr, R. E., 1978. Asset prices in an exchange economy, Econometrica 46, 1429-1445.

Lustig, H. N. and S. G. V. Nieuwerburgh, 2005. Housing collateral, consumption insurance, and risk premia: An empirical perspective, Journal of Finance 60, 1167-1219. 
Lynch, A. W. and S. Tan, 2011. Explaining the magnitude of liquidity premia: The roles of return predictability, wealth shocks, and state-dependent transaction costs, Journal of Finance 66, 1329-1368.

Malloy, C. J., T. J. Moskowitz, and A. Vissing-Jørgensen, 2009. Long-run stockholder consumption risk and asset returns, Journal of Finance 64, 2427-2480.

Márquez, E., B. Nieto., and G. Rubio, 2014. Stock returns with consumption and illiquidity risks, International Review of Economics and Finance 29, 57-74..

Merton, R. C., 1969. Lifetime portfolio selection under uncertainty: The continuous-time case, Review of Economics and Statistics 51, 247-257.

Næs, R., J. A. Skjeltorp, and B. A. Ødegaard, 2011. Stock market liquidity and the business cycle, Journal of Finance 66, 139-176.

Parker, J. A. and C. Julliard, 2005. Consumption risk and the cross-section of expected returns, Journal of Political Economy 113, 185-222.

Pastor, L. and R. F. Stambaugh, 2003. Liquidity risk and expected stock returns, Journal of Political Economy 111, 642-685.

Petkova, R., 2006. Do the Fama-French factors proxy for innovations in predictive variables? Journal of Finance 61, 581-612.

Rubinstein, M., 1976. The valuation of uncertain income streams and the pricing of options, Bell Journal of Economics and Management Science 7, 407-425.

Sadka, R., 2006. Momentum and post-earnings-announcement drift anomalies: The role of liquidity risk, Journal of Financial Economics 80, 309-349.

Samuelson, P. A., 1969. Lifetime portfolio selection by dynamic stochastic programming, Review of Economics and Statistics 51, 239-246.

Savov, A., 2011. Asset pricing with garbage, Journal of Finance 66, 177-201.

Shanken, J., 1992. On the estimation of beta-pricing models, Review of Financial Studies 5, 1-33.

Sharpe, W. F., 1964. Capital asset prices: A theory of market equilibrium under conditions of risk, Journal of Finance 19, 425-42.

Vissing-Jørgensen, A. and O. P. Attanasio, 2003. Stock-market participation, intertemporal substitution, and risk-aversion, American Economic Review 93, 383-391.

Yogo, M., 2006. A consumption-based explanation of expected stock returns, Journal of Finance 61, 539580 . 


\section{Table 1}

\section{Descriptive statistics}

This table reports the descriptive statistics for the main variables of the excess market returns (mkt), consumption growth of nondurables and services $(\mathrm{cg})$, consumption to aggregate wealth ratio (cay), consumption growth of nondurable goods over 36 months (cg36), durable consumption growth (cgd), and three liquidity risk factors. The notation $l i q^{P S}$ stands for the aggregate liquidity innovation of Pastor and Stambaugh (2003) from 1962 to 2010, $l i q^{L M}$ for Liu's (2006) mimicking liquidity risk factor from 1959 to 2010, and liq Sadka for Sadka's (2006) aggregate liquidity innovation based on the variable component of price impact from 1983 to 2010.

\begin{tabular}{|c|c|c|c|c|c|c|c|c|}
\hline & $m k t$ & $c g$ & cay & $\operatorname{cg} 36$ & $c g d$ & $l i q^{P S}$ & $l i q^{L M}$ & $l i q^{S a d k a}$ \\
\hline \multicolumn{9}{|c|}{ Descriptive statistics } \\
\hline Mean & 0.568 & 0.138 & 0.471 & 4.170 & 0.423 & 0.002 & 0.594 & 0.000 \\
\hline Stdev & 4.581 & 0.291 & 2.128 & 3.692 & 2.775 & 0.062 & 4.031 & 0.006 \\
\hline \multicolumn{9}{|c|}{ Correlation } \\
\hline$c g$ & 0.129 & 1 & & & & & & \\
\hline cay & -0.040 & 0.064 & 1 & & & & & \\
\hline$c g 36$ & 0.086 & 0.187 & 0.233 & 1 & & & & \\
\hline$c g d$ & -0.029 & 0.218 & -0.007 & 0.118 & 1 & & & \\
\hline$l i q^{P S}$ & 0.301 & 0.053 & 0.036 & 0.047 & 0.042 & 1 & & \\
\hline$l i q^{L M}$ & -0.739 & -0.106 & 0.109 & 0.060 & 0.030 & -0.167 & 1 & \\
\hline$l i q^{S a d k a}$ & 0.166 & 0.099 & -0.113 & 0.024 & 0.078 & 0.231 & 0.017 & 1 \\
\hline
\end{tabular}


Table 2

\section{Liquidity betas estimated from time-series regressions}

This table reports liquidity betas for each of the 25 Fama-French value-weighted size and book-to-market portfolios. Risk loadings are estimated from a multiple time-series regression over the entire sample period. Specifically, we estimate the liquidity beta according to the following equation:

$$
R_{i}=\alpha_{i}+\beta_{c g, i} f_{c g}+\beta_{m k t, i} f_{m k t}+\beta_{l i q, i} f_{l i q}+e_{i},
$$

where $f_{c g}, f_{m k t}$, and $f_{l i q}$ denote the aggregate consumption growth of nondurable goods and services, the market factor, and the liquidity factor, respectively. Our test uses three alternative liquidity risk factors: the aggregate liquidity innovation of Pastor and Stambaugh (2003) from 1962 to 2010 in Panel A, Liu's (2006) mimicking liquidity risk factor from 1959 to 2010 in Panel B, and Sadka's (2006) aggregate liquidity innovation based on the variable component of price impact from 1983 to 2010 in Panel C.

\begin{tabular}{|c|c|c|c|c|c|}
\hline & Low & 2 & 3 & 4 & High \\
\hline \multicolumn{6}{|c|}{ Panel A: Pastor and Stambaugh (2003) liquidity factor } \\
\hline Small & $\begin{array}{r}0.021 \\
(0.56)\end{array}$ & $\begin{array}{r}0.021 \\
(0.64)\end{array}$ & $\begin{array}{c}0.038 \\
(1.39)\end{array}$ & $\begin{array}{c}0.054 \\
(2.04)\end{array}$ & $\begin{array}{c}0.060 \\
(2.05)\end{array}$ \\
\hline 2 & $\begin{array}{c}0.018 \\
(0.64)\end{array}$ & $\begin{array}{r}0.047 \\
(2.05)\end{array}$ & $\begin{array}{c}0.046 \\
(2.15)\end{array}$ & $\begin{array}{c}0.042 \\
(1.94)\end{array}$ & $\begin{array}{c}0.034 \\
(1.28)\end{array}$ \\
\hline 3 & $\begin{array}{c}0.013 \\
(0.55)\end{array}$ & $\begin{array}{c}0.050 \\
(2.86)\end{array}$ & $\begin{array}{c}0.048 \\
(2.74)\end{array}$ & $\begin{array}{c}0.031 \\
(1.64)\end{array}$ & $\begin{array}{r}0.051 \\
(2.17)\end{array}$ \\
\hline 4 & $\begin{array}{c}0.013 \\
(0.73)\end{array}$ & $\begin{array}{c}0.039 \\
(2.68)\end{array}$ & $\begin{array}{c}0.038 \\
(2.28)\end{array}$ & $\begin{array}{c}0.018 \\
(1.03)\end{array}$ & $\begin{array}{c}0.031 \\
(1.33)\end{array}$ \\
\hline Big & $\begin{array}{c}-0.030 \\
(-2.29)\end{array}$ & $\begin{array}{c}0.028 \\
(2.19)\end{array}$ & $\begin{array}{c}0.015 \\
(0.95)\end{array}$ & $\begin{array}{c}-0.023 \\
(-1.26)\end{array}$ & $\begin{array}{c}-0.019 \\
(-0.81)\end{array}$ \\
\hline \multicolumn{6}{|c|}{ Panel B: Liu (2006) liquidity factor } \\
\hline Small & $\begin{array}{c}-0.147 \\
(-2.00)\end{array}$ & $\begin{array}{c}0.045 \\
(0.71)\end{array}$ & $\begin{array}{c}0.226 \\
(4.40)\end{array}$ & $\begin{array}{c}0.329 \\
(6.76)\end{array}$ & $\begin{array}{r}0.447 \\
(8.43)\end{array}$ \\
\hline 2 & $\begin{array}{c}-0.353 \\
(-6.66)\end{array}$ & $\begin{array}{l}-0.025 \\
(-0.58)\end{array}$ & $\begin{array}{c}0.118 \\
(2.92)\end{array}$ & $\begin{array}{c}0.190 \\
(4.68)\end{array}$ & $\begin{array}{r}0.218 \\
(4.36)\end{array}$ \\
\hline 3 & $\begin{array}{l}-0.353 \\
(-8.21)\end{array}$ & $\begin{array}{l}-0.016 \\
(-0.47)\end{array}$ & $\begin{array}{c}0.130 \\
(3.87)\end{array}$ & $\begin{array}{c}0.192 \\
(5.39)\end{array}$ & $\begin{array}{r}0.228 \\
(5.05)\end{array}$ \\
\hline 4 & $\begin{array}{l}-0.319 \\
(-9.97)\end{array}$ & $\begin{array}{c}0.036 \\
(1.30)\end{array}$ & $\begin{array}{c}0.106 \\
(3.33)\end{array}$ & $\begin{array}{c}0.133 \\
(3.96)\end{array}$ & $\begin{array}{r}0.209 \\
(4.73)\end{array}$ \\
\hline Big & $\begin{array}{c}-0.077 \\
(-9.97)\end{array}$ & $\begin{array}{c}0.076 \\
(1.30)\end{array}$ & $\begin{array}{c}0.103 \\
(3.33)\end{array}$ & $\begin{array}{c}0.192 \\
(3.96)\end{array}$ & $\begin{array}{r}0.205 \\
(4.73)\end{array}$ \\
\hline \multicolumn{6}{|c|}{ Panel C: Sadka (2006) liquidity factor } \\
\hline Small & $\begin{array}{c}0.025 \\
(0.06)\end{array}$ & $\begin{array}{c}0.331 \\
(0.87)\end{array}$ & $\begin{array}{c}0.582 \\
(2.01)\end{array}$ & $\begin{array}{c}0.569 \\
(2.01)\end{array}$ & $\begin{array}{c}0.965 \\
(3.11)\end{array}$ \\
\hline 2 & $\begin{array}{c}0.011 \\
(0.03)\end{array}$ & $\begin{array}{c}0.407 \\
(1.58)\end{array}$ & $\begin{array}{c}0.401 \\
(1.75)\end{array}$ & $\begin{array}{c}0.367 \\
(1.49)\end{array}$ & $\begin{array}{c}0.615 \\
(2.03)\end{array}$ \\
\hline 3 & $\begin{array}{l}-0.047 \\
(-0.16)\end{array}$ & $\begin{array}{c}0.093 \\
(0.47)\end{array}$ & $\begin{array}{c}0.231 \\
(1.15)\end{array}$ & $\begin{array}{c}0.216 \\
(0.96)\end{array}$ & $\begin{array}{c}0.584 \\
(2.27)\end{array}$ \\
\hline 4 & $\begin{array}{l}-0.011 \\
(-0.05)\end{array}$ & $\begin{array}{c}0.429 \\
(2.51)\end{array}$ & $\begin{array}{c}0.401 \\
(1.97)\end{array}$ & $\begin{array}{c}0.149 \\
(0.75)\end{array}$ & $\begin{array}{r}0.512 \\
(1.97)\end{array}$ \\
\hline Big & $\begin{array}{l}-0.298 \\
(-2.07)\end{array}$ & $\begin{array}{c}0.155 \\
(0.95)\end{array}$ & $\begin{array}{c}-0.039 \\
(-0.22)\end{array}$ & $\begin{array}{c}0.064 \\
(0.28)\end{array}$ & $\begin{array}{c}0.134 \\
(0.47)\end{array}$ \\
\hline
\end{tabular}




\section{Table 3}

\section{Risk premium}

This table reports the cross-sectional regression results using the monthly portfolio returns of the 25 Fama-French value-weighted size and book-to-market portfolios. To estimate the risk premium, we run the following regression:

$$
R_{i, t}=\gamma_{0}+\gamma_{c g} \beta_{i, c g}+\gamma_{m k t} \beta_{i, m k t}+\gamma_{l i q} \beta_{i, l i q}+e_{i, t},
$$

where $\beta_{i, c g}$ denotes the consumption beta, $\beta_{i, m k t}$ denotes the market beta, and $\beta_{i, l i q}$ denotes the liquidity beta. These betas are estimated from a multiple time-series regression for each testing portfolio over the entire sample period. We report the model parameters $(\gamma \mathrm{s})$ estimated using both the ordinary least squares (OLS) and the generalized least squares (GLS) regressions. The estimated coefficients are in percentage. For robustness, we report different $t$-statistics: the FM $t$-ratio of Fama and MacBeth (1973), the SH $t$-ratio of Shanken (1992) with errors-in-variables adjustment, the JW t-ratio of Jagannathan and Wang (1996), and the KRS $t$-ratio of Kan, Robotti, and Shanken (2013) under potentially misspecified models. The test uses three alternative liquidity risk factors: the aggregate liquidity innovation of Pastor and Stambaugh (2003) from 1962 to 2010 in Panel A, Liu's (2006) mimicking liquidity risk factor from 1959 to 2010 in Panel B, and Sadka's (2006) aggregate liquidity innovation based on the variable component of price impact from 1983 to 2010 in Panel C.

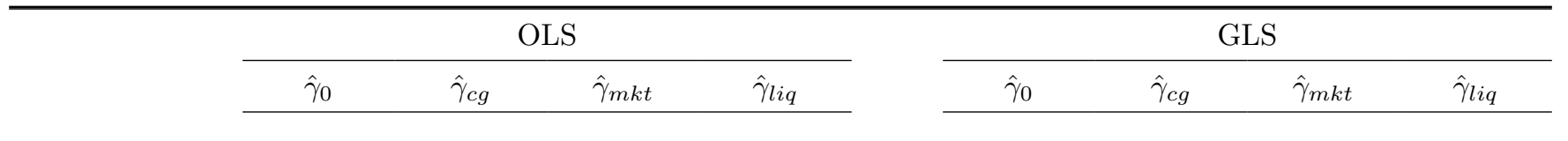

Panel A: Pastor and Stambaugh (2003) liquidity factor

\begin{tabular}{lllllllll}
\hline Estimates & 1.47 & 0.13 & -0.81 & 5.67 & 1.46 & 0.04 & -0.85 & 2.65 \\
FM $t$-ratio & 4.04 & 1.88 & -2.02 & 4.62 & 6.82 & 0.78 & -2.99 & 3.10 \\
SH $t$-ratio & 2.57 & 1.20 & -1.37 & 2.97 & 5.82 & 0.67 & -2.72 & 2.67 \\
JW $t$-ratio & 1.97 & 0.90 & -1.10 & 2.32 & 4.99 & 0.59 & -2.42 & 2.57 \\
KRS $t$-ratio & 1.85 & 0.58 & -1.04 & 2.16 & 4.61 & 0.45 & -2.24 & 1.88 \\
\hline
\end{tabular}

Panel B: Liu (2006) liquidity factor

\begin{tabular}{|c|c|c|c|c|c|c|c|c|}
\hline Estimates & 0.48 & 0.18 & 0.17 & 0.90 & 0.89 & 0.09 & -0.30 & 0.73 \\
\hline FM $t$-ratio & 1.03 & 2.43 & 0.34 & 4.04 & 3.25 & 1.62 & -0.92 & 4.00 \\
\hline $\mathrm{SH} t$-ratio & 0.87 & 2.06 & 0.29 & 3.61 & 3.06 & 1.53 & -0.88 & 3.89 \\
\hline JW $t$-ratio & 0.84 & 2.04 & 0.28 & 3.63 & 2.92 & 1.45 & -0.85 & 3.92 \\
\hline KRS $t$-ratio & 0.74 & 1.15 & 0.25 & 3.67 & 2.43 & 0.90 & -0.74 & 3.71 \\
\hline \multicolumn{9}{|c|}{ Panel C: Sadka (2006) liquidity factor } \\
\hline Estimates & 1.73 & 0.08 & -1.01 & 0.38 & 2.25 & 0.06 & -1.52 & 0.45 \\
\hline FM $t$-ratio & 3.04 & 1.16 & -1.65 & 1.99 & 9.11 & 1.31 & -4.32 & 4.22 \\
\hline $\mathrm{SH} t$-ratio & 2.45 & 0.95 & -1.37 & 1.62 & 6.91 & 1.02 & -3.70 & 3.28 \\
\hline JW $t$-ratio & 2.51 & 1.02 & -1.41 & 1.40 & 6.45 & 1.08 & -3.43 & 3.49 \\
\hline KRS $t$-ratio & 2.42 & 0.66 & -1.37 & 1.24 & 5.88 & 0.75 & -3.15 & 2.69 \\
\hline
\end{tabular}


Table 4

\section{Price of covariance risk}

This table reports the cross-sectional regression estimates using monthly returns of the 25 Fama-French valueweighted size and book-to-market portfolios. The regression is:

$$
R_{i, t}=\lambda_{0}+\lambda_{c g} \operatorname{Cov}\left(R_{i}, c g\right)+\lambda_{m k t} \operatorname{Cov}\left(R_{i}, m k t\right)+\lambda_{l i q} \operatorname{Cov}\left(R_{i}, \operatorname{liq}\right)+e_{i, t},
$$

where $\operatorname{Cov}\left(R_{i}, c g\right)$ stands for the covariance between portfolio $i$ 's return and consumption growth, $\operatorname{Cov}\left(R_{i}, m k t\right)$ for the covariance between portfolio $i$ 's return and excess value-weighted market return, and $\operatorname{Cov}\left(R_{i}, \operatorname{liq}\right)$ for the covariance between portfolio $i$ 's return and the liquidity factor. These covariances are estimated for each testing portfolio over the entire sample period. We report model parameters ( $\lambda \mathrm{s}$, in percentage) estimated using both the ordinary least squares (OLS) and generalized least squares (GLS) regressions. For robustness, we apply different $t$-statistics: the FM $t$-ratio of Fama and MacBeth (1973), the SH $t$-ratio of Shanken (1992) with errors-in-variables adjustment, the JW $t$-ratio of Jagannathan and Wang (1996), and the KRS $t$-ratio of Kan, Robotti, and Shanken (2013) under potentially misspecified models. Our test uses three alternative liquidity risk factors: the aggregate liquidity innovation of Pastor and Stambaugh (2003) from 1962 to 2010 in Panel A, Liu's (2006) mimicking liquidity risk factor from 1959 to 2010 in Panel B, and Sadka's (2006) aggregate liquidity innovation based on the variable component of price impact from 1983 to 2010 in Panel C.

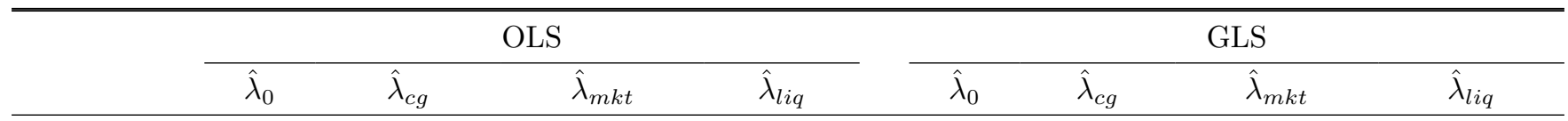

Panel A: Pastor and Stambaugh (2003) liquidity factor

\begin{tabular}{lrrrrrrrr}
\hline Estimates & 1.47 & 13346.65 & -1465.09 & 2090.93 & 1.46 & 4523.35 & -924.19 & 1049.16 \\
FM $t$-ratio & 4.04 & 2.06 & -4.86 & 4.86 & 6.82 & 0.99 & -4.47 & 3.54 \\
SH $t$-ratio & 2.57 & 1.30 & -3.06 & 3.06 & 5.82 & 0.85 & -3.77 & 2.99 \\
JW $t$-ratio & 1.97 & 0.97 & -2.38 & 2.31 & 4.99 & 0.73 & -3.19 & 2.69 \\
KRS $t$-ratio & 1.85 & 0.62 & -2.63 & 2.22 & 4.61 & 0.56 & -2.63 & 2.00 \\
\hline
\end{tabular}

Panel B: Liu (2006) liquidity factor

\begin{tabular}{lrrrrrrrr}
\hline Estimates & 0.48 & 15456.17 & 544.77 & 1337.89 & 0.89 & 8181.65 & 137.79 & 796.36 \\
FM $t$-ratio & 1.03 & 2.41 & 1.39 & 3.39 & 3.25 & 1.65 & 0.50 & 2.72 \\
SH $t$-ratio & 0.87 & 2.02 & 1.17 & 2.83 & 3.06 & 1.55 & 0.47 & 2.55 \\
JW $t$-ratio & 0.84 & 1.97 & 1.09 & 2.73 & 2.92 & 1.46 & 0.46 & 2.63 \\
KRS $t$-ratio & 0.74 & 1.09 & 0.85 & 2.50 & 2.43 & 0.91 & 0.37 & 2.24 \\
\hline
\end{tabular}

Panel C: Sadka (2006) liquidity factor

\begin{tabular}{lrrrrrrrr}
\hline Estimates & 1.73 & 8981.44 & -791.33 & 9931.56 & 2.25 & 6859.74 & -1062.87 & 11892.11 \\
FM $t$-ratio & 3.04 & 1.11 & -2.84 & 2.10 & 9.11 & 1.21 & -5.60 & 4.49 \\
SH $t$-ratio & 2.45 & 0.90 & -2.28 & 1.69 & 6.91 & 0.92 & -4.14 & 3.35 \\
JW $t$-ratio & 2.51 & 0.88 & -2.41 & 1.49 & 6.45 & 0.89 & -3.91 & 3.61 \\
KRS $t$-ratio & 2.42 & 0.58 & -2.23 & 1.31 & 5.88 & 0.65 & -3.66 & 2.73 \\
\hline
\end{tabular}


Table 5

Cross-sectional $R^{2}$ and HJ distance

This table reports the sample cross-sectional $R^{2}$, the test of equality of cross-sectional $R^{2}$ as in Kan, Robotti, and Shanken (2013), and the test of equality of HJ distance (Hansen and Jagannathan (1997)) as in Kan and Robotti (2009). We examine three consumption-based asset pricing models: the traditional CCAPM, the Epstein-Zin model and the liquidity-extended Epstein-Zin model. The notation $d R^{2}$ is the $R^{2}$ of the liquidity-extended Epstein-Zin model minus that of the CCAPM or the Epstein-Zin model. Under the potentially misspecified model, we calculate the $p$-value, which is presented in parentheses next to $d R^{2}$, to test the null that the cross-sectional $R^{2}$ of two competing models are equal. The symbol $d H J$ is the squared HJ distance of CCAPM or Epstein-Zin model minus that of liquidity-extended Epstein-Zin model. The numbers in parentheses (next to $d H J$ ) calculated under potentially misspecified models are the $p$-values associated with the hypothesis that the squared HJ distances of two competing models are equal. Test assets are the 25 Fama-French value-weighted size and book-to-market portfolios. We report the results using both the ordinary least squares (OLS) and generalized least squares (GLS) estimates. We apply three alternative liquidity risk factors to the tests: the aggregate liquidity innovation of Pastor and Stambaugh (2003) from 1962 to 2010 in Panel A, Liu's (2006) mimicking liquidity risk factor from 1959 to 2010 in Panel B, and Sadka's (2006) aggregate liquidity innovation based on the variable component of price impact from 1983 to 2010 in Panel C.

\begin{tabular}{|c|c|c|c|c|c|}
\hline & \multirow[t]{2}{*}{ Traditional CCAPM } & \multirow[t]{2}{*}{ Epstein-Zin model } & \multirow[t]{2}{*}{ Liquidity-extended model } & \multicolumn{2}{|c|}{ Tests of equality } \\
\hline & & & & Traditional CCAPM & Epstein-Zin model \\
\hline \multicolumn{6}{|c|}{ Panel A: Pastor and Stambaugh (2003) liquidity factor } \\
\hline$R^{2}(\mathrm{OLS})$ & $R^{2}=0.0 \%$ & $R^{2}=29.8 \%$ & $R^{2}=59.1 \%$ & $d R^{2}=59.0 \%(0.016)$ & $d R^{2}=29.3 \%(0.027)$ \\
\hline$R^{2}(\mathrm{GLS})$ & $R^{2}=0.3 \%$ & $R^{2}=10.9 \%$ & $R^{2}=27.3 \%$ & $d R^{2}=26.9 \%(0.028)$ & $d R^{2}=16.4 \%(0.045)$ \\
\hline HJ distance & $H J=0.436$ & $H J=0.427$ & $H J=0.408$ & $d H J=0.024(0.130)$ & $d H J=0.016(0.131)$ \\
\hline \multicolumn{6}{|c|}{ Panel B: Liu (2006) liquidity factor } \\
\hline$R^{2}(\mathrm{OLS})$ & $R^{2}=0.0 \%$ & $R^{2}=37.5 \%$ & $R^{2}=67.2 \%$ & $d R^{2}=67.2 \%(0.000)$ & $d R^{2}=29.8 \%(0.012)$ \\
\hline$R^{2}(\mathrm{GLS})$ & $R^{2}=0.2 \%$ & $R^{2}=14.0 \%$ & $R^{2}=23.9 \%$ & $d R^{2}=23.7 \%(0.001)$ & $d R^{2}=9.9 \%(0.025)$ \\
\hline HJ distance & $H J=0.408$ & $H J=0.403$ & $H J=0.324$ & $d H J=0.061(0.000)$ & $d H J=0.057(0.000)$ \\
\hline \multicolumn{6}{|c|}{ Panel C: Sadka (2006) liquidity factor } \\
\hline$R^{2}(\mathrm{OLS})$ & $R^{2}=9.3 \%$ & $R^{2}=51.7 \%$ & $R^{2}=69.0 \%$ & $d R^{2}=59.6 \%(0.029)$ & $d R^{2}=17.2 \%(0.190)$ \\
\hline$R^{2}(\mathrm{GLS})$ & $R^{2}=0.3 \%$ & $R^{2}=23.8 \%$ & $R^{2}=47.5 \%$ & $d R^{2}=47.2 \%(0.000)$ & $d R^{2}=23.6 \%(0.005)$ \\
\hline HJ distance & $H J=0.667$ & $H J=0.654$ & $H J=0.594$ & $d H J=0.093(0.042)$ & $d H J=0.075(0.038)$ \\
\hline
\end{tabular}


Table 6

\section{Robustness on risk premium and the price of covariance risk}

With different settings for robustness tests, this table reports the estimated risk premium $\left(\gamma_{l i q}\right)$ and the price of covariance risk $\left(\lambda_{l i q}\right)$ with respect to the three alternative liquidity risk factors. Test assets are the 25 Fama-French value-weighted size and book-to-market portfolios, except for Panel D. In Panels A and C, we incorporate the consumption-to-wealth ratio (cay and cg cay) of Lettau and Ludvigson (2001) and durable consumption growth (cgd) of Yogo (2006) into the liquidity-extended consumption model. In Panel B, we follow Parker and Julliard (2005) and measure consumption growth based on nondurable goods over 36 months (cg36). In Panel D, we expand the 25 Fama-French portfolios with five value-weighted industry portfolios. We classify the five industries following Gomes, Kogan, and Yogo (2009). We report the estimated risk premium and price of covariance risk using both the ordinary least squares (OLS) and generalized least squares (GLS) regressions. The estimated coefficients are in percentage. For robustness, we report different $t$-statistics: the FM $t$-ratio of Fama and MacBeth (1973), the SH $t$-ratio of Shanken (1992) with errors-in-variables adjustment, the JW $t$-ratio of Jagannathan and Wang (1996), and the KRS $t$-ratio of Kan, Robotti, and Shanken (2013) under potentially misspecified models. The three alternative liquidity risk factors are the aggregate liquidity innovation of Pastor and Stambaugh (PS) from 1962 to 2010. Liu's (2006) liquidity risk factor from 1959 to 2010, and Sadka's (2006) aggregate liquidity innovation based on the variable component of price impact from 1983 to 2010.

\begin{tabular}{|c|c|c|c|c|c|c|c|c|c|c|c|c|}
\hline & \multicolumn{2}{|c|}{ OLS } & \multicolumn{2}{|c|}{ GLS } & \multicolumn{2}{|c|}{ OLS } & \multicolumn{2}{|c|}{ GLS } & \multicolumn{2}{|r|}{ OLS } & \multicolumn{2}{|r|}{ GLS } \\
\hline & $\hat{\gamma}_{l i q}$ & $\hat{\lambda}_{l i q}$ & $\hat{\gamma}_{l i q}$ & $\hat{\lambda}_{l i q}$ & $\hat{\gamma}_{l i q}$ & $\hat{\lambda}_{l i q}$ & $\hat{\gamma}_{l i q}$ & $\hat{\lambda}_{l i q}$ & $\hat{\gamma}_{l i q}$ & $\hat{\lambda}_{l i q}$ & $\hat{\gamma}_{l i q}$ & $\hat{\lambda}_{l i q}$ \\
\hline & \multicolumn{4}{|c|}{ PS (2003) liquidity factor } & \multicolumn{4}{|c|}{ Liu (2006) liquidity factor } & \multicolumn{4}{|c|}{ Sadka (2006) liquidity factor } \\
\hline \multicolumn{13}{|c|}{ Panel A: cay (Lettau and Ludvigson (2001)) } \\
\hline Estimates & 5.25 & 2080.00 & 2.87 & 1084.52 & 0.85 & 1349.87 & 0.73 & 809.46 & 0.39 & 10142.47 & 0.46 & 12490.40 \\
\hline FM $t$-ratio & 4.35 & 4.80 & 3.24 & 3.63 & 4.17 & 3.46 & 4.02 & 2.75 & 2.07 & 2.26 & 4.03 & 4.31 \\
\hline SH $t$-ratio & 2.67 & 2.89 & 2.68 & 2.95 & 3.16 & 2.24 & 3.89 & 2.54 & 1.62 & 1.75 & 3.08 & 3.18 \\
\hline JW $t$-ratio & 2.18 & 2.26 & 2.50 & 2.57 & 3.45 & 2.03 & 3.92 & 2.61 & 1.37 & 1.50 & 3.40 & 3.59 \\
\hline KRS $t$-ratio & 1.86 & 2.04 & 1.87 & 1.99 & 3.22 & 1.97 & 3.68 & 2.20 & 1.25 & 1.34 & 2.41 & 2.48 \\
\hline \multicolumn{13}{|c|}{ Panel B: cg36 (Parker and Julliard (2005)) } \\
\hline Estimates & 4.64 & 1619.96 & 2.76 & 1059.05 & 0.83 & 1521.23 & 0.70 & 824.15 & 0.49 & 13023.23 & 0.44 & 11929.91 \\
\hline FM $t$-ratio & 4.24 & 4.32 & 3.21 & 3.57 & 3.63 & 3.44 & 3.88 & 2.56 & 2.83 & 2.99 & 4.14 & 4.48 \\
\hline $\mathrm{SH} t$-ratio & 2.74 & 2.73 & 2.72 & 2.96 & 3.43 & 3.13 & 3.83 & 2.48 & 2.15 & 2.23 & 3.28 & 3.41 \\
\hline JW t-ratio & 2.47 & 2.36 & 2.60 & 2.63 & 3.23 & 3.16 & 3.82 & 2.52 & 1.89 & 2.01 & 3.54 & 3.72 \\
\hline KRS $t$-ratio & 2.12 & 1.94 & 1.89 & 1.95 & 3.03 & 2.06 & 3.57 & 1.94 & 1.53 & 1.61 & 2.67 & 2.81 \\
\hline \multicolumn{13}{|c|}{ Panel C: cgd (Yogo (2006)) } \\
\hline Estimates & 2.38 & 897.92 & 2.27 & 888.78 & 0.85 & 381.60 & 0.69 & 455.94 & 0.41 & 10554.70 & 0.46 & 12320.29 \\
\hline FM $t$-ratio & 2.04 & 2.08 & 2.56 & 2.85 & 3.80 & 0.86 & 3.76 & 1.27 & 2.82 & 2.75 & 4.25 & 4.48 \\
\hline $\mathrm{SH} t$-ratio & 1.47 & 1.48 & 2.20 & 2.41 & 3.25 & 0.68 & 3.61 & 1.15 & 2.26 & 2.16 & 3.26 & 3.31 \\
\hline JW t-ratio & 1.45 & 1.42 & 2.13 & 2.19 & 3.48 & 0.73 & 3.72 & 1.19 & 2.05 & 2.02 & 3.25 & 3.25 \\
\hline KRS $t$-ratio & 1.02 & 1.05 & 1.48 & 1.55 & 3.29 & 0.38 & 3.45 & 0.82 & 1.36 & 1.35 & 2.57 & 2.55 \\
\hline \multicolumn{13}{|c|}{ Panel D: FF25+5 industry (Lewellen, Nagel, and Shanken (2010)) } \\
\hline Estimates & 5.12 & 1848.55 & 2.14 & 838.95 & 0.76 & 1333.18 & 0.67 & 684.81 & 0.25 & 6373.98 & 0.25 & 6624.67 \\
\hline FM $t$-ratio & 4.12 & 4.24 & 2.76 & 3.23 & 3.58 & 3.53 & 3.93 & 2.47 & 1.37 & 1.44 & 2.56 & 2.77 \\
\hline $\mathrm{SH} t$-ratio & 2.93 & 2.97 & 2.48 & 2.86 & 3.38 & 3.19 & 3.87 & 2.35 & 1.25 & 1.31 & 2.26 & 2.38 \\
\hline JW $t$-ratio & 2.18 & 2.10 & 2.32 & 2.52 & 3.40 & 3.11 & 3.92 & 2.35 & 1.15 & 1.22 & 2.41 & 2.68 \\
\hline KRS $t$-ratio & 2.16 & 2.10 & 1.80 & 1.94 & 3.42 & 2.99 & 3.70 & 1.99 & 0.92 & 0.94 & 1.61 & 1.78 \\
\hline
\end{tabular}




\section{Table 7}

\section{Robustness on cross-sectional $R^{2}$ and HJ distance}

This table reports the test of equality of cross-sectional $R^{2}$ and HJ distance obtained under different settings. Our tests are based on the 25 Fama-French value-weighted size and book-to-market portfolios, unless otherwise stated. In Panels A and B, we respectively evaluate our model relative to the CCAPM and the Epstein-Zin model. We incorporate the consumption-to-wealth ratio (cay and $c g \cdot c a y$ ) of Lettau and Ludvigson (2001) and durable consumption growth $(c g d)$ of Yogo (2006) into the CCAPM, the Epstein-Zin model, and the liquidity-extended Epstein-Zin model. We also follow Parker and Julliard (2005) and measure consumption growth based on nondurable goods over 36 months (cg36). In addition, we expand the 25 Fama-French value-weighted size and book-to-market portfolios with five value-weighted industry portfolios. The classification of the five industries is based on Gomes, Kogan, and Yogo (2009). We use these 30 testing portfolios to compare our model with the CCAPM and the EpsteinZin model. The symbol $d R^{2}$ is the $R^{2}$ of the liquidity-extended Epstein-Zin model (with different specifications) minus that of the CCAPM (with different specifications) in Panel A and Epstein-Zin model (with different specifications) in Panel $\mathrm{B}, p\left(d R^{2}\right)$ (in parentheses) calculated under potentially misspecified models is the $p$-value associated with the hypothesis that the cross-sectional $R^{2}$ of two competing models are equal, $d H J$ is the squared HJ distance of CCAPM (with different specifications) in Panel A and Epstein-Zin model (with different specifications) in Panel B minus that of the liquidity-extended Epstein-Zin model (with different specifications), and $p(d H J)$ (in parentheses) calculated under potentially misspecified models is the $p$-value associated with the hypothesis that the squared HJ distances of two competing models are equal. We report the results using both the ordinary least squares (OLS) and generalized least squares (GLS) estimates. Our tests are based on three alternative liquidity risk factors: the aggregate liquidity innovation of Pastor and Stambaugh (2003) from 1962 to 2010 in columns 1, 2, and 3; Liu's (2006) mimicking liquidity risk factor from 1959 to 2010 in columns 4, 5, and 6; and Sadka's (2006) aggregate liquidity innovation based on the variable component of price impact from 1983 to 2010 in columns 7, 8, and 9 .

Panel A: traditional CCAPM and liquidity-extended Epstein-Zin model

\begin{tabular}{|c|c|c|c|c|c|c|c|c|}
\hline \multicolumn{3}{|c|}{$\begin{array}{l}\text { Pastor and Stambaugh } \\
(2003) \text { liquidity factor }\end{array}$} & \multicolumn{3}{|c|}{$\begin{array}{l}\text { Liu (2006) } \\
\text { liquidity factor }\end{array}$} & \multicolumn{3}{|c|}{$\begin{array}{l}\text { Sadka (2006) } \\
\text { liquidity factor }\end{array}$} \\
\hline 1 & 2 & 3 & 4 & 5 & 6 & 7 & 8 & 9 \\
\hline $\begin{array}{c}d R^{2}(\mathrm{OLS}) \\
p\left(d R^{2}\right) \\
\end{array}$ & $\begin{array}{c}d R^{2} \text { (GLS) } \\
\quad p\left(d R^{2}\right) \\
\end{array}$ & $\begin{array}{c}d H J \\
p(d H J) \\
\end{array}$ & $\begin{array}{c}d R^{2}(\mathrm{OLS}) \\
p\left(d R^{2}\right) \\
\end{array}$ & $\begin{array}{c}d R^{2}(\mathrm{GLS}) \\
p\left(d R^{2}\right) \\
\end{array}$ & $\begin{array}{c}d H J \\
p(d H J) \\
\end{array}$ & $\begin{array}{c}d R^{2}(\mathrm{OLS}) \\
p\left(d R^{2}\right) \\
\end{array}$ & $\begin{array}{c}d R^{2}(\mathrm{GLS}) \\
p\left(d R^{2}\right) \\
\end{array}$ & $\begin{array}{c}d H J \\
p(d H J)\end{array}$ \\
\hline \multicolumn{9}{|c|}{ cay: Lettau and Ludvigson (2001) } \\
\hline $\begin{array}{c}0.592 \\
(0.029) \\
\end{array}$ & $\begin{array}{c}0.252 \\
(0.046) \\
\end{array}$ & $\begin{array}{c}0.026 \\
(0.188) \\
\end{array}$ & $\begin{array}{r}0.687 \\
(0.012) \\
\end{array}$ & $\begin{array}{c}0.217 \\
(0.004) \\
\end{array}$ & $\begin{array}{c}0.048 \\
(0.001) \\
\end{array}$ & $\begin{array}{c}0.438 \\
(0.048) \\
\end{array}$ & $\begin{array}{c}0.419 \\
(0.000) \\
\end{array}$ & $\begin{array}{c}0.109 \\
(0.054) \\
\end{array}$ \\
\hline \multicolumn{9}{|c|}{ cg36: Parker and Julliard (2005) } \\
\hline 0.314 & 0.275 & 0.022 & 0.295 & 0.191 & 0.052 & 0.642 & 0.458 & 0.081 \\
\hline$(0.104)$ & $(0.018)$ & $(0.161)$ & $(0.049)$ & $(0.004)$ & $(0.000)$ & $(0.152)$ & $(0.000)$ & $(0.064)$ \\
\hline
\end{tabular}

cgd: Yogo (2006)

\begin{tabular}{ccccccccc}
\hline 0.241 & 0.234 & 0.022 & 0.200 & 0.178 & 0.059 & 0.447 & 0.465 & 0.100 \\
$(0.093)$ & $(0.034)$ & $(0.168)$ & $(0.101)$ & $(0.016)$ & $(0.000)$ & $(0.059)$ & $(0.000)$ & $(0.030)$ \\
\hline
\end{tabular}

FF25+5 industry: Lewellen, Nagel, and Shanken (2010)

\begin{tabular}{ccccccccc}
\hline 0.496 & 0.212 & 0.020 & 0.633 & 0.188 & 0.066 & 0.424 & 0.253 & 0.058 \\
$(0.042)$ & $(0.023)$ & $(0.130)$ & $(0.000)$ & $(0.001)$ & $(0.000)$ & $(0.104)$ & $(0.004)$ & $(0.066)$ \\
\hline
\end{tabular}

[Cont.] 
Table 7

\section{Continued}

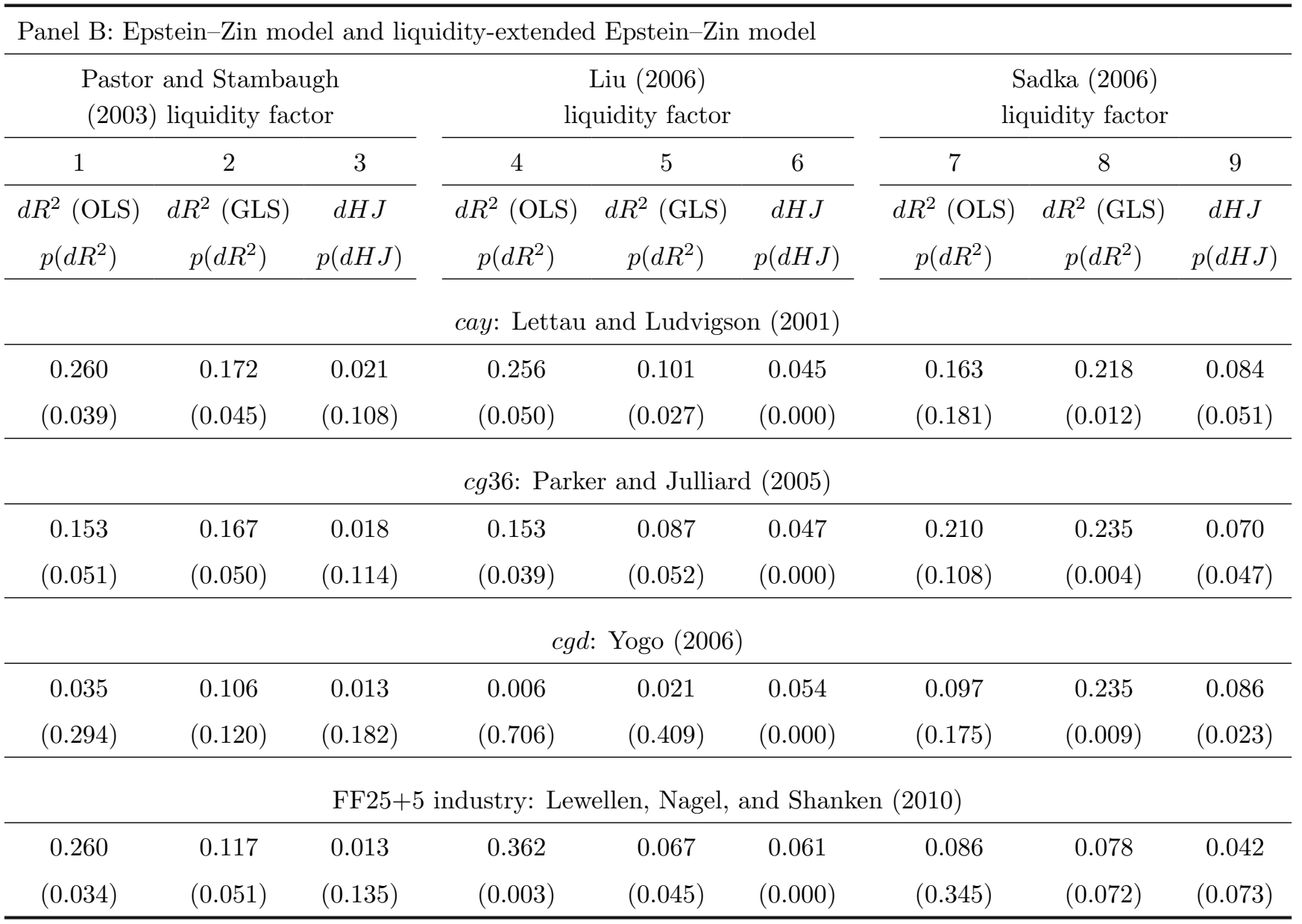


Table 8

Robustness on risk premium and the price of covariance risk with other pricing models

With different settings for robustness tests, this table reports the estimated risk premium $\left(\gamma_{l i q}\right)$ and the price of covariance risk $\left(\lambda_{l i q}\right)$ with respect to the three alternative liquidity risk factors. Test assets are the 25 Fama-French value-weighted size and book-to-market portfolios. In Panel A, we incorporate the liquidity factor into the traditional CAPM. In Panel B, we incorporate the liquidity factor into the FF3FM. In Panel C, we we incorporate the liquidity factor into the Jagannathan and Wang (1996) model (JW). We report the estimated risk premium and price of covariance risk using both the ordinary least squares (OLS) and the generalized least squares (GLS) regressions. The estimated coefficients are in percentage. For robustness, we report different $t$-statistics: the FM $t$-ratio of Fama and MacBeth (1973), the SH $t$-ratio of Shanken (1992) with errors-in-variables adjustment, the JW $t$-ratio of Jagannathan and Wang (1996), and the KRS $t$-ratio of Kan, Robotti, and Shanken (2013) under potentially misspecified models. The three alternative liquidity risk factors are the aggregate liquidity innovation of Pastor and Stambaugh (2003) from 1962 to 2010, Liu's (2006) mimicking liquidity risk factor from 1959 to 2010, and Sadka's (2006) aggregate liquidity innovation based on the variable component of price impact from 1983 to 2010 .

\begin{tabular}{|c|c|c|c|c|c|c|c|c|c|c|c|c|}
\hline & \multicolumn{2}{|r|}{ OLS } & \multicolumn{2}{|c|}{ GLS } & \multicolumn{2}{|c|}{ OLS } & \multicolumn{2}{|c|}{ GLS } & \multicolumn{2}{|r|}{ OLS } & \multicolumn{2}{|c|}{ GLS } \\
\hline & $\hat{\gamma}_{l i q}$ & $\hat{\lambda}_{l i q}$ & $\hat{\gamma}_{l i q}$ & $\hat{\lambda}_{l i q}$ & $\hat{\gamma}_{l i q}$ & $\hat{\lambda}_{l i q}$ & $\hat{\gamma}_{l i q}$ & $\hat{\lambda}_{l i q}$ & $\hat{\gamma}_{l i q}$ & $\hat{\lambda}_{l i q}$ & $\hat{\gamma}_{l i q}$ & $\hat{\lambda}_{l i q}$ \\
\hline & \multicolumn{4}{|c|}{$\begin{array}{l}\text { Pastor and Stambaugh } \\
(2003) \text { liquidity factor }\end{array}$} & \multicolumn{4}{|c|}{$\begin{array}{c}\text { Liu (2006) } \\
\text { liquidity factor }\end{array}$} & \multicolumn{4}{|c|}{$\begin{array}{c}\text { Sadka }(2006) \\
\text { liquidity factor }\end{array}$} \\
\hline \multicolumn{13}{|c|}{ Panel A: CAPM } \\
\hline Estimates & 6.65 & 2403.37 & 2.62 & 1035.46 & 0.85 & 1574.33 & 0.70 & 789.45 & 0.42 & 10142.47 & 0.44 & 11.932 .06 \\
\hline FM $t$-ratio & 4.57 & 4.84 & 3.06 & 3.49 & 3.77 & 3.82 & 3.87 & 2.70 & 2.11 & 2.28 & 4.16 & 4.51 \\
\hline $\mathrm{SH} t$-ratio & 2.82 & 2.93 & 2.67 & 2.99 & 3.57 & 3.46 & 3.83 & 2.62 & 1.71 & 1.83 & 3.30 & 3.43 \\
\hline JW t-ratio & 2.16 & 2.13 & 2.52 & 2.62 & 3.36 & 3.47 & 3.83 & 2.75 & 1.50 & 1.62 & 3.52 & 3.68 \\
\hline KRS $t$-ratio & 2.90 & 2.69 & 1.82 & 1.94 & 3.34 & 3.58 & 3.60 & 2.30 & 1.37 & 1.47 & 2.67 & 2.81 \\
\hline
\end{tabular}

Panel B: FF3FM (Fama and French (1993))

\begin{tabular}{|c|c|c|c|c|c|c|c|c|c|c|c|c|}
\hline Estimates & 2.45 & 919.66 & 1.76 & 715.48 & 0.43 & -169.20 & 0.60 & 205.90 & 0.53 & 14011.45 & 0.46 & 12597.88 \\
\hline FM t-ratio & 2.13 & 2.31 & 1.96 & 2.30 & 2.07 & -0.40 & 3.07 & 0.58 & 4.07 & 4.18 & 4.04 & 4.32 \\
\hline $\mathrm{SH} t$-ratio & 1.89 & 2.02 & 1.79 & 2.08 & 2.03 & -0.39 & 3.03 & 0.56 & 3.06 & 3.05 & 3.12 & 3.21 \\
\hline JW $t$-ratio & 1.87 & 1.94 & 1.75 & 1.95 & 2.03 & -0.39 & 3.03 & 0.55 & 3.16 & 2.92 & 3.32 & 3.33 \\
\hline KRS $t$-ratio & 1.45 & 1.47 & 1.22 & 1.37 & 1.82 & -0.26 & 2.85 & 0.47 & 1.65 & 1.63 & 2.53 & 2.55 \\
\hline \multicolumn{13}{|c|}{ Panel C: JW (Jagannathan and Wang (1996)) } \\
\hline Estimates & 7.06 & 2550.56 & 2.49 & 974.78 & 0.98 & 1976.78 & 0.69 & 832.05 & 0.43 & 11553.23 & 0.44 & 12236.09 \\
\hline FM $t$-ratio & 4.54 & 4.67 & 2.72 & 3.07 & 4.43 & 4.97 & 3.81 & 2.84 & 2.29 & 2.50 & 4.07 & 4.48 \\
\hline $\mathrm{SH} t$-ratio & 2.62 & 2.66 & 2.34 & 2.60 & 3.45 & 3.42 & 3.65 & 2.56 & 1.70 & 1.83 & 3.00 & 3.17 \\
\hline JW $t$-ratio & 1.93 & 1.86 & 2.22 & 2.28 & 2.92 & 3.22 & 3.62 & 2.83 & 1.57 & 1.73 & 3.09 & 3.31 \\
\hline KRS $t$-ratio & 2.33 & 2.26 & 1.49 & 1.59 & 2.86 & 3.69 & 3.36 & 2.41 & 1.53 & 1.69 & 2.54 & 2.66 \\
\hline
\end{tabular}


Table 9

\section{Robustness on cross-sectional $R^{2}$ and HJ distance with other pricing models}

This table reports the results of the equality test of cross-sectional $R^{2} \mathrm{~s}$ and the equality test of HJ distances under different settings. Our tests are based on the 25 Fama-French value-weighted size and book-to-market portfolios. We incorporate the liquidity factor into the traditional CAPM, the FF3FM, and the Jagannathan and Wang (1996) model (JW), respectively. We then evaluate these augmented models relative to the original models. The symbol $d R^{2}$ is the $R^{2}$ of the augmented model (with different specifications) minus that of the original model (with different specifications), $p\left(d R^{2}\right)$ (in parentheses) calculated under potentially misspecified models is the $p$-value associated with the hypothesis that the cross-sectional $R^{2}$ of two competing models are equal, $d H J$ is the squared HJ distance of the original model (with different specifications) minus that of the augmented model (with different specifications), and $p(d H J)$ (in parentheses) calculated under potentially misspecified models is the $p$-value associated with the hypothesis that the squared HJ distances of two competing models are equal. We report the results using both the ordinary least squares (OLS) and generalized least squares (GLS) estimates. Our tests are based on three alternative liquidity risk factors: the aggregate liquidity innovation of Pastor and Stambaugh (2003) from 1962 to 2010 in columns 1, 2, and 3; Liu's (2006) mimicking liquidity risk factor from 1959 to 2010 in columns 4, 5, and 6; and Sadka's (2006) aggregate liquidity innovation based on the variable component of price impact from 1983 to 2010 in columns 7,8 , and 9 .

\begin{tabular}{|c|c|c|c|c|c|c|c|c|}
\hline \multicolumn{3}{|c|}{$\begin{array}{l}\text { Pastor and Stambaugh } \\
\text { (2003) liquidity factor }\end{array}$} & \multicolumn{3}{|c|}{$\begin{array}{l}\text { Liu (2006) } \\
\text { liquidity factor }\end{array}$} & \multicolumn{3}{|c|}{$\begin{array}{l}\text { Sadka (2006) } \\
\text { liquidity factor }\end{array}$} \\
\hline 1 & 2 & 3 & 4 & 5 & 6 & 7 & 8 & 9 \\
\hline$d R^{2}(\mathrm{OLS})$ & $d R^{2}(\mathrm{GLS})$ & $d H J$ & $d R^{2}(\mathrm{OLS})$ & $d R^{2}(\mathrm{GLS})$ & $d H J$ & $d R^{2}(\mathrm{OLS})$ & $d R^{2}$ (GLS) & $d H J$ \\
\hline$p\left(d R^{2}\right)$ & $p\left(d R^{2}\right)$ & $p(d H J)$ & $p\left(d R^{2}\right)$ & $p\left(d R^{2}\right)$ & $p(d H J)$ & $p\left(d R^{2}\right)$ & $p\left(d R^{2}\right)$ & $p(d H J)$ \\
\hline \multicolumn{9}{|c|}{ Panel A: CAPM } \\
\hline 0.473 & 0.160 & 0.016 & 0.545 & 0.100 & 0.056 & 0.238 & 0.267 & 0.075 \\
\hline$(0.006)$ & $(0.052)$ & $(0.135)$ & $(0.000)$ & $(0.021)$ & $(0.000)$ & $(0.004)$ & $(0.141)$ & $(0.040)$ \\
\hline \multicolumn{9}{|c|}{ Panel B: FF3FM (Fama and French (1993)) } \\
\hline 0.041 & 0.069 & 0.008 & 0.001 & 0.005 & 0.023 & 0.115 & 0.219 & 0.054 \\
\hline$(0.141)$ & $(0.169)$ & $(0.262)$ & $(0.792)$ & $(0.641)$ & $(0.001)$ & $(0.100)$ & $(0.010)$ & $(0.095)$ \\
\hline \multicolumn{9}{|c|}{ Panel C: JW (Jagannathan and Wang (1996)) } \\
\hline 0.304 & 0.125 & 0.008 & 0.402 & 0.109 & 0.052 & 0.232 & 0.193 & 0.079 \\
\hline$(0.029)$ & $(0.096)$ & $(0.357)$ & $(0.001)$ & $(0.019)$ & $(0.000)$ & $(0.010)$ & $(0.102)$ & $(0.039)$ \\
\hline
\end{tabular}




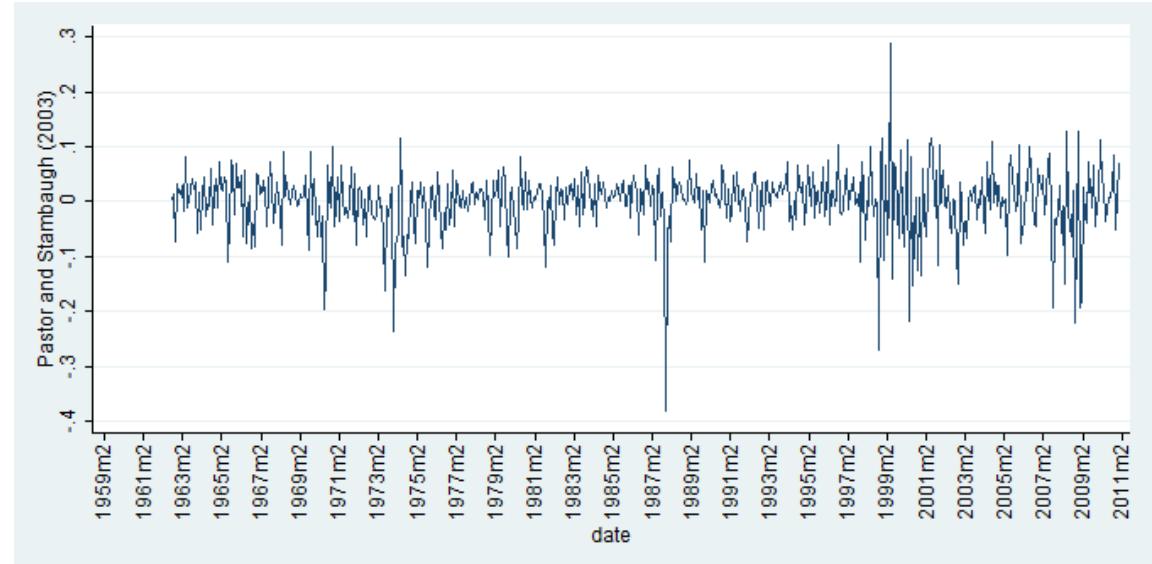

Panel A: Pastor and Stambaugh (2003) liquidity factor

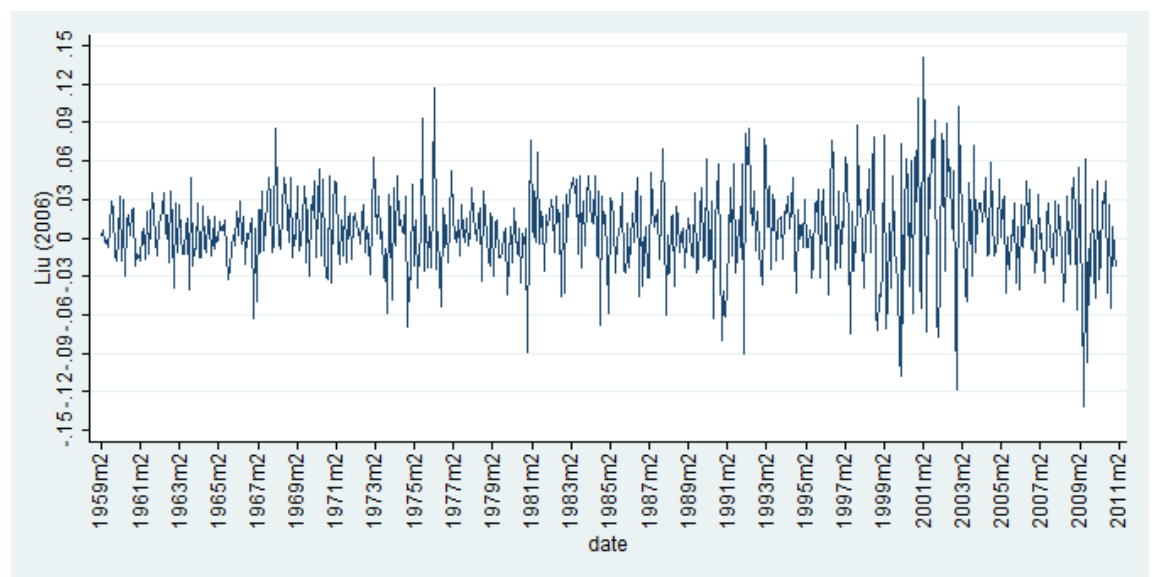

Panel B: Liu (2006) liquidity factor

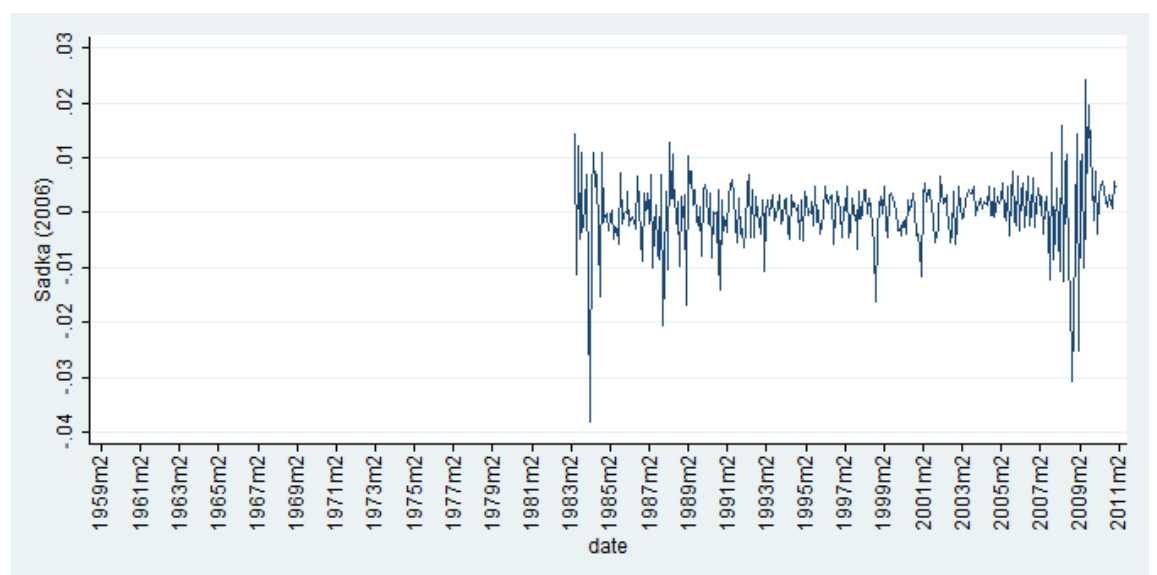

Panel C: Sadka (2006) liquidity factor

Figure 1: Time series plots of market liquidity.

This figure plots the aggregate liquidity innovation of Pastor and Stambaugh (2003) from 1962 to 2010 in Panel A, Liu's (2006) mimicking liquidity risk factor from 1959 to 2010 in Panel B, and Sadka's (2006) aggregate liquidity innovation based on the variable component of price impact from 1983 to 2010 in Panel C. 

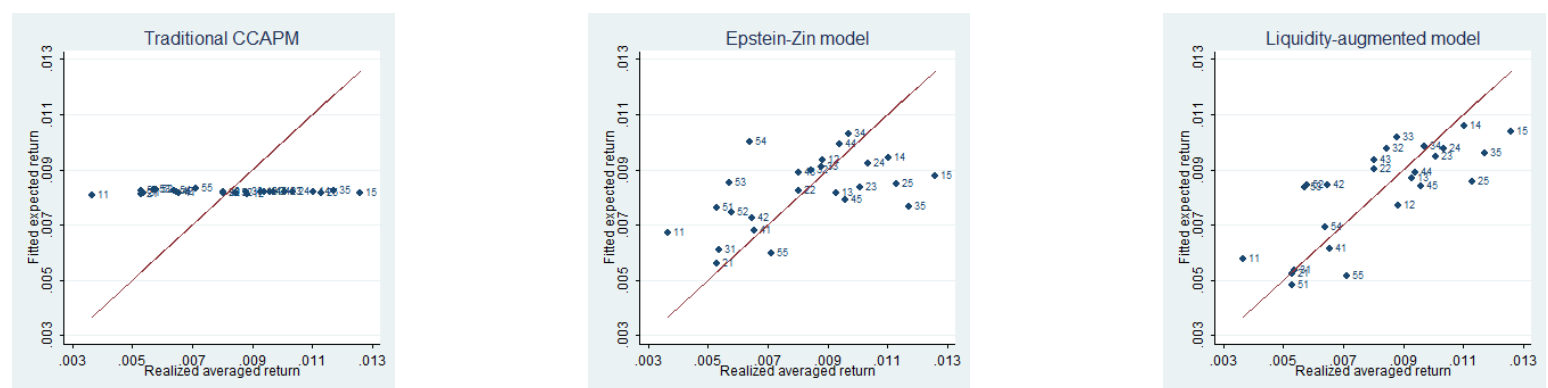

Panel A: Pastor and Stambaugh (2003) liquidity factor
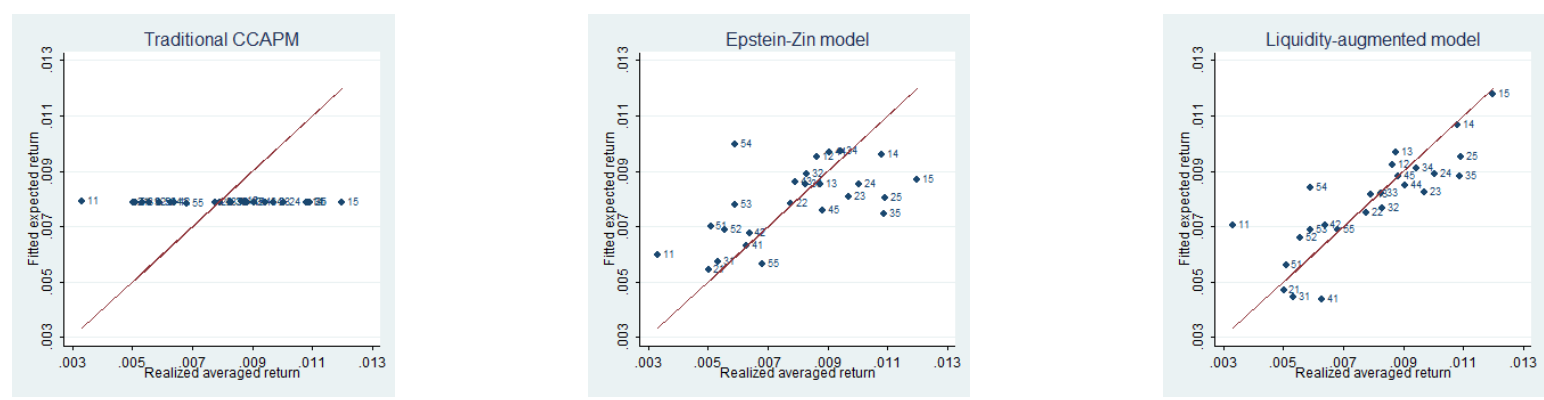

Panel B: Liu (2006) liquidity factor
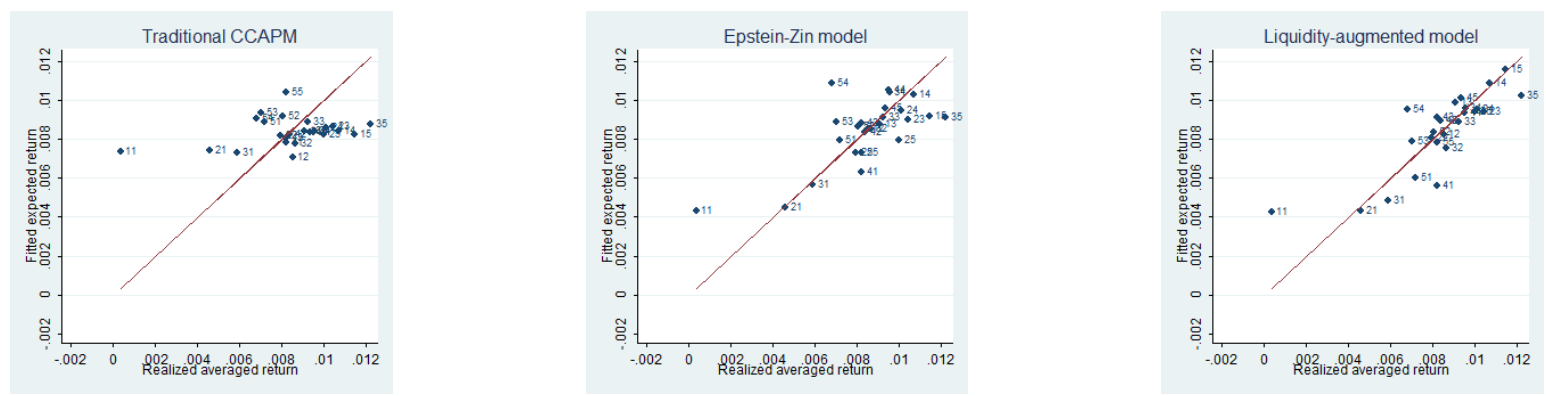

Panel C: Sadka (2006) liquidity factor

\section{Figure 2: Fitted versus realized returns.}

These figures plot the fitted returns versus realized returns using the OLS estimates. The horizonal axis shows the realized average portfolio return and the vertical axis shows the portfolio return fitted by different models. The straight line is the 45-degree line from the origin. Test portfolios are the 25 Fama-French value-weighted size and book-to-market portfolios. The fitted expected returns for the traditional CCAPM are calculated with $E[R]=\gamma_{0}+\gamma_{c g} \beta_{i, c g}$. The fitted expected returns for the Epstein-Zin model are calculated with $E[R]=\gamma_{0}+$ $\gamma_{c g} \beta_{i, c g}+\gamma_{m k t} \beta_{i, m k t}$. The fitted expected returns for the liquidity-extended Epstein-Zin model are calculated with $E[R]=\gamma_{0}+\gamma_{c g} \beta_{i, c g}+\gamma_{m k t} \beta_{i, m k t}+\gamma_{l i q} \beta_{i, l i q}$. The consumption betas, market betas, and liquidity betas are estimated from a multiple time-series regression for each portfolio over the entire sample period. Each two-digit number in the figure indicates one portfolio. The first digit denotes the size quintile ( 1 representing the smallest and 5 the largest), and the second digit denotes the book-to-market quintile (1 representing the lowest and 5 the highest). We use three alternative liquidity risk factors: the aggregate liquidity innovation of Pastor and Stambaugh (2003) from 1962 to 2010 in Panel A, Liu's (2006) mimicking liquidity risk factor from 1959 to 2010 in Panel B, and Sadka's (2006) aggregate liquidity innovation based on the variable component of price impact from 1983 to 2010 in Panel C. 


\section{APPENDIX A}

In this appendix, we derive our liquidity-extended Epstein-Zin model. We assume a representative consumer and rely on the model of Samuelson (1969) and Merton (1969) to characterize the representative consumer's multiperiod consumption and investment decision. The decision interval is a discrete time period and each period is of unit length. The representative consumer's utility follows the Epstein and Zin $(1989,1991)$ recursive function, which is a recursive aggregation over current consumption and a certainty equivalent of future utility. It has the form:

$$
U_{t}=\left\{(1-\beta) C_{t}^{1-\rho}+\beta\left[E\left(U_{t+1}^{1-\theta}\right)\right]^{\frac{1-\rho}{1-\theta}}\right\}^{\frac{1}{1-\rho}}
$$

where $C_{t}$ denotes the consumption at time $t, U_{t+1}$ denotes the continuation value of the future consumption plan, $\beta$ denotes the subjective discount factor, $\theta$ denotes the coefficient of relative risk

aversion, and $\frac{1}{\rho}$ denotes the elasticity of intertemporal substitution (EIS) in consumption. When $\theta=\rho$, the recursive utility function collapses to the traditional constant relative risk aversion (CRRA) utility function. We later show that the recursive utility allows us to take into account the excess market returns in our liquidity-extended Epstein-Zin model.

\section{The liquidity effect}

The return (i.e., 1 plus the rate of return) of risky asset $i$ after netting out liquidity costs is,

$$
R_{i, t+1}^{n}=\frac{D_{i, t+1}+P_{i, t+1}-L C_{i, t+1}}{P_{i, t}}=R_{i, t+1}-l c_{i, t+1},
$$

where $P_{i, t+1}$ is the ex-dividend stock $i$ 's price at $t+1, D_{i, t+1}$ is the dividend per share, $L C_{i, t+1}$ is the per-share cost of selling stock $i,{ }^{20} R_{i, t+1}$ is the return before liquidity costs, and $l c_{i, t+1}$ is the

\footnotetext{
${ }^{20}$ Similar to Acharya and Pedersen (2005), $D_{i, t+1}$ and $L C_{i, t+1}$ follow the first-order autoregressive processes.
} 
relative time-varying liquidity costs. In the spirit of Acharya and Pedersen (2005), investors can buy stock $i$ at $P_{i, t+1}$ but have to sell it at $P_{i, t+1}-L C_{i, t+1}$.

Broadly, liquidity costs stem from transaction costs ${ }^{21}$ thin and infrequent trading, and price impact. For thinly and infrequently traded securities, liquidity traders may have to sell at low prices and to buy at high prices. For stocks with trading having high impact on price, selling (buying) can result in large price decrease (increase).

Let the representative consumer's portfolio weight of the risky asset $i$ be $\omega_{i, t}(i=1,2, \ldots, n)$, the weight of the risk-free asset is then $1-\sum_{i=1}^{n} \omega_{i, t}$. Suppose the representative consumer closes her position at $t+1$. To take into account the liquidity effects on dynamic wealth, we follow Lynch and Tan (2011) by assuming that wealth evolves according to the following equation:

$$
W_{t+1}=\left(1-L_{t+1}\right)\left(W_{t}-C_{t}\right)\left[R_{f, t+1}+\sum_{i=1}^{n} \omega_{i t}\left(R_{i, t+1}-R_{f, t+1}\right)\right]
$$

where $C_{t}$ denotes consumption at $t, W_{t}$ denotes wealth at $t, L_{t+1}$ denotes the liquidity costs per dollar of the portfolio value, and $R_{f, t+1}$ denotes the return (i.e., one plus the rate of return) of the risk-free asset for the period from $t$ to $t+1$. We assume that trading on the liquid risk-free asset incurs no liquidity costs.

In Eq. (A-3), $1-L_{t+1}$ reflects the effect of liquidity costs. Chordia, Roll, and Subrahmanyam (2000), Hasbrouck and Seppi (2001), and Acharya and Pedersen (2005) show that individual stock liquidity tends to co-move with market liquidity. As the representative consumer holds a portfolio of risky assets, $1-L_{t+1}$ captures the aggregate liquidity shocks on the budget constraints over time, i.e., the aggregate distortion due to liquidity costs on dynamic wealth. Holding other factors

\footnotetext{
${ }^{21}$ While transaction costs are not taken into account by the traditional CCAPM, they are the subject currently generating much research interests, see, for example, Amihud and Mendelson (1986), Jacoby, Fowler, and Gottesman (2000), Lo, MacKinlay, and Wang (2004), Acharya and Pedersen (2005), Jang, Koo, Liu, and Loewenstein (2007), and Lynch and Tan (2011).
} 
constant, investors' wealth is affected more negatively when trading incurs higher liquidity costs. The loss in wealth associated with the trading activity is attributed to liquidity risk, which is shown later in our liquidity-extended Epstein-Zin model. This is aligns with the argument that liquidity risk arises from consumption and solvency constraints (Liu, 2010; and Chien and Lustig, 2010).

\section{The liquidity-extended Epstein-Zin model}

The representative consumer maximizes life-time utility function as follows:

$$
\max _{C_{s}, \omega_{i, s}, \forall s, i} E_{t}\left[\sum_{s=t}^{T-1} U\left(C_{s}\right)+B\left(W_{T}\right)\right]
$$

where $U\left(C_{s}\right)$ is the utility from consumption at time $s$ and $B\left(W_{T}\right)$ is the ending bequest function that is monotonically increasing and strictly concave.

Eq. (A-4) indicates that the representative consumer makes decisions with variables $C_{s}$ and $\omega_{i, s}$ $(i=1,2, \ldots, n)$ so as to maximize the expected value of the lifetime utility. Based on Eq. (A-3), we can use stochastic dynamic programming to obtain the following first-order condition (FOC) of the optimal choice problem in Eq. (A-4):

$$
E_{t}\left[\frac{U_{C}\left(C_{t+1}^{*}, t+1\right)}{U_{C}\left(C_{t}^{*}, t\right)}\left(1-L_{t+1}\right)\left(R_{i, t+1}-R_{f, t+1}\right)\right]=0
$$

where $U_{C}$ denotes the partial differentiation with respect to the consumption, $C$. According to Epstein and Zin (1989, 1991), we can have:

$$
\frac{U_{C}\left(C_{t+1}^{*}, t+1\right)}{U_{C}\left(C_{t}^{*}, t\right)}=\beta^{\frac{1-\theta}{1-\rho}}\left(\frac{C_{t+1}}{C_{t}}\right)^{-\rho \frac{1-\theta}{1-\rho}} R_{W, t+1}^{\frac{\rho-\theta}{1-\rho}}
$$


where $R_{W, t+1}$ is the return to wealth from $t$ to $t+1$. Without the liquidity effect, the asset pricing implication of Epstein-Zin model is a two-factor model that mixes the traditional CAPM with the traditional CCAPM.

According to Eqs. (A-5) and (A-6), the Euler equation of our liquidity-adjusted consumption model is

$$
E_{t}\left[\beta^{\frac{1-\theta}{1-\rho}}\left(\frac{C_{t+1}}{C_{t}}\right)^{-\rho \frac{1-\theta}{1-\rho}} R_{W, t+1}^{\frac{\rho-\theta}{1-\rho}}\left(1-L_{t+1}\right)\left(R_{i, t+1}-R_{f, t+1}\right)\right]=0
$$

From Eq. (A-7), we have

$$
M_{t+1}=\beta^{\frac{1-\theta}{1-\rho}}\left(\frac{C_{t+1}}{C_{t}}\right)^{-\rho \frac{1-\theta}{1-\rho}} R_{W, t+1}^{\frac{\rho-\theta}{1-\rho}}\left(1-L_{t+1}\right) .
$$

This can be rewritten as:

$$
E\left[M_{t+1}\left(R_{i, t+1}-R_{f, t+1}\right)\right]=0 .
$$

Following Cochrane (2005) and Yogo (2006), we can linearize $M_{t+1}$ in a vector $f_{t}$ of $F$ underlying factors as follows:

$$
-\frac{M_{t+1}}{E\left[M_{t+1}\right]}=a+b^{\prime} f_{t+1}
$$

The beta representation of Eq. (A-9) is

$$
E\left[R_{i, t+1}-R_{f, t+1}\right]=\gamma^{\prime} \beta_{i}
$$

where $\gamma=E\left[\left(f_{t+1}-E\left[f_{t+1}\right]\right)\left(f_{t+1}-E\left[f_{t+1}\right]\right)^{\prime}\right] b$ and $\beta_{i}=E\left[\left(f_{t+1}-E\left[f_{t+1}\right]\right)\left(f_{t+1}-E\left[f_{t+1}\right]\right)^{\prime}\right]^{-1} E\left[\left(f_{t+1}-E\left[f_{t+1}\right]\right)\left(R_{i, t+1}-R_{f, t+1}\right)\right]$. Taking the log of both sides of Eq. (A-8), we have 


$$
m_{t+1}=\frac{1-\theta}{1-\rho} \log (\beta)-\frac{1-\theta}{1-\rho} \rho \Delta c_{t+1}+\frac{\rho-\theta}{1-\rho} r_{W, t+1}+\log \left(1-L_{t+1}\right)
$$

where lowercase letters denote the log of uppercase letters.

Using Eq. (A-12), we can write the covariance between $m_{t+1}$ and the stock/portfolio return as:

$$
\begin{aligned}
\operatorname{Cov}\left(m_{t+1}, R_{i, t+1}\right) & =-\frac{1-\theta}{1-\rho} \rho \operatorname{Cov}\left(\Delta c_{t+1}, R_{i, t+1}\right) \\
& +\frac{\rho-\theta}{1-\rho} \operatorname{Cov}\left(r_{W, t+1}, R_{i, t+1}\right)+\operatorname{Cov}\left[\log \left(1-L_{t+1}\right), R_{i, t+1}\right] .
\end{aligned}
$$

According to Yogo (2006), we can approximate $M_{t+1}$ as:

$$
\begin{aligned}
-\frac{M_{t+1}}{E\left[M_{t+1}\right]} & =-1-m_{t+1}+E\left[m_{t+1}\right] \\
& =a+b_{1} \Delta c_{t+1}+b_{2} r_{W, t+1}+b_{3} \log \left(1-L_{t+1}\right),
\end{aligned}
$$

where $a=-1-b_{1} E\left[\Delta c_{t+1}\right]-b_{2} E\left[r_{W, t+1}\right]-b_{3} E\left[\log \left(1-L_{t+1}\right)\right], b_{1}=\frac{1-\theta}{1-\rho} \rho, b_{2}=\frac{\rho-\theta}{\rho-1}$, and $b_{3}=-1$.

Using Eqs. (A-11), (A-12), (A-13), and (A-14), we can write the beta representation as:

$$
E\left[R_{i}-R_{f}\right]=\gamma_{c g} \beta_{i, c g}+\gamma_{m k t} \beta_{i, R_{W}}+\gamma_{l i q} \beta_{i, l i q}
$$

where $\beta_{i, c g}$ denotes the consumption beta, $\beta_{i, R_{W}}$ denotes the return to wealth beta, and $\beta_{i, l i q}$ denotes the liquidity beta; $\gamma_{c g}, \gamma_{m k t}$, and $\gamma_{l i q}$ are the prices of consumption risk, market risk, and liquidity risk. 


\section{APPENDIX B}

Yogo (2006) embeds durable goods consumption into the Epstein-Zin $(1989,1991)$ utility function, which provides framework to study the effect of liquidity on the cross-sectional asset prices. In this appendix, we alternatively derive our liquidity-extended Epstein-Zin model in the spirit of Yogo (2006).

We begin with a representative consumer's multiperiod consumption and investment decision model of Samuelson (1969) and Merton (1969). The consumer chooses to buy $C_{t}$ units of nondurable consumption goods at each time $t$. We assume that liquidity, $L_{t}$, evolves over time according to the following AR(1) process (e.g., Pastor and Stambaugh, 2003; and Acharya and Pedersen, 2005):

$$
L_{t+1}=a_{0}+a_{1} L_{t}+u_{t}
$$

The intraperiod utility of the representative consumer has the following form:

$$
u(C, L)=\left[(1-\alpha) C^{1-\delta}+\alpha L^{1-\delta}\right]^{\frac{1}{1-\delta}},
$$

where $\alpha$ is between 0 and 1 and $\frac{1}{\delta}$ denotes the elasticity of substitution between consumption and liquidity. The preference as in Eq. (B-2) is the same as those used in Yogo (2006), Gu and Huang (2013), and Lioui and Malo (2014) except that the intraperiod utility here is defined over combinations of consumption and liquidity. ${ }^{22}$

We further assume that the representative consumer's utility follows the Epstein and Zin (1989, 1991) recursive function, which is a recursive aggregation over two components: (1) current nondurable and services consumption and liquidity; and (2) a certainty equivalent of future utility. It has the form:

\footnotetext{
${ }^{22}$ The intraperiod utility in Yogo (2006) is defined over nondurable and services consumption and durable consumption. The intraperiod utility in Gu and Huang (2013) and Lioui and Malo (2014) is defined over nondurable and services consumption and money.
} 


$$
U_{t}=\left\{(1-\beta) u\left(C_{t}, L_{t}\right)^{1-\rho}+\beta\left(E\left[U_{t+1}^{1-\theta}\right]\right)^{\frac{1-\rho}{1-\theta}}\right\}^{\frac{1}{1-\rho}}
$$

where notations are defined in Eq. (A-1).

Let the representative consumer's portfolio weight of the risky asset $i$ be $\omega_{i, t}(i=1,2, \ldots, n)$, the weight of the risk-free asset is then $1-\sum_{i=1}^{n} \omega_{i, t}$. Suppose the representative consumer closes his/her position at $t+1$. We can have the following wealth dynamic:

$$
W_{t+1}=\left(W_{t}-C_{t}-P_{t} u_{t}\right)\left[R_{f, t+1}+\sum_{i=1}^{n} \omega_{i, t}\left(R_{i, t+1}-R_{f, t+1}\right)\right]
$$

where $W_{t}$ denotes wealth at $t, P_{t}$ denotes the price of additional liquidity in terms of nondurable consumption goods at $t, u_{t}$ is defined in Eq. (B-1), and $R_{f, t+1}$ denotes the return (i.e., one plus the rate of return) of the risk-free asset for the period from $t$ to $t+1$. We assume that trading on the liquid risk-free asset incurs no liquidity costs.

Following Yogo (2006), we can write the intertemporal marginal rate of substitution as

$$
M_{t+1}=\beta^{\frac{1-\theta}{1-\rho}}\left(\frac{C_{t+1}}{C_{t}}\right)^{-\rho \frac{1-\theta}{1-\rho}}\left(\frac{v\left(L_{t+1} / C_{t+1}\right)}{v\left(L_{t} / C_{t}\right)}\right)^{\frac{(\delta-\rho)(1-\theta)}{1-\rho}} R_{W, t+1}^{\frac{\rho-\theta}{1-\rho}}
$$

where $v\left(\frac{L}{C}\right)=\left[1-\alpha+\alpha\left(\frac{L}{C}\right)^{1-\delta}\right]^{\frac{1}{1-\delta}}$ and $R_{W, t+1}$ is the return to wealth from $t$ to $t+1$.

We can apply the dynamic programming to obtain the Euler equation of the liquidity-extended consumption model as follows:

$$
E\left[\beta^{\frac{1-\theta}{1-\rho}}\left(\frac{C_{t+1}}{C_{t}}\right)^{-\rho \frac{1-\theta}{1-\rho}}\left(\frac{v\left(L_{t+1} / C_{t+1}\right)}{v\left(L_{t} / C_{t}\right)}\right)^{\frac{(\delta-\rho)(1-\theta)}{1-\rho}} R_{W, t+1}^{\frac{\rho-\theta}{1-\rho}}\left(R_{i, t+1}-R_{f, t+1}\right)\right]=0
$$

Following Cochrane (2005) and Yogo (2006), we can linearize $M_{t+1}$ in a vector $f_{t}$ of $F$ underlying factors as follows: 


$$
-\frac{\beta^{\frac{1-\theta}{1-\rho}}\left(\frac{C_{t+1}}{C_{t}}\right)^{-\rho \frac{1-\theta}{1-\rho}}\left(\frac{v\left(L_{t+1} / C_{t+1}\right)}{v\left(L_{t} / C_{t}\right)}\right)^{\frac{(\delta-\rho)(1-\theta)}{1-\rho}} R_{W, t+1}^{\frac{\rho-\theta}{1-\rho}}}{E\left[\beta^{\frac{1-\theta}{1-\rho}}\left(\frac{C_{t+1}}{C_{t}}\right)^{-\rho \frac{1-\theta}{1-\rho}}\left(\frac{v\left(L_{t+1} / C_{t+1}\right)}{v\left(L_{t} / C_{t}\right)}\right)^{\frac{(\delta-\rho)(1-\theta)}{1-\rho}} R_{W, t+1}^{\frac{\rho-\theta}{1-\rho}}\right]}=a+b^{\prime} f_{t+1} .
$$

The beta representation of Eq. (B-7) is

$$
E\left[R_{i, t+1}-R_{f, t+1}\right]=\gamma^{\prime} \beta_{i}
$$

where $\gamma=E\left[\left(f_{t+1}-E\left[f_{t+1}\right]\right)\left(f_{t+1}-E\left[f_{t+1}\right]\right)^{\prime}\right] b$ and $\beta_{i}=E\left[\left(f_{t+1}-E\left[f_{t+1}\right]\right)\left(f_{t+1}-E\left[f_{t+1}\right]\right)^{\prime}\right]^{-1} E\left[\left(f_{t+1}-E\left[f_{t+1}\right]\right)\left(R_{i, t+1}-R_{f, t+1}\right)\right]$.

Following Yogo (2006), we can approximate Eq. (B-5) to the following log form:

$$
m_{t+1}=\frac{1-\theta}{1-\rho} \log (\beta)-\frac{1-\theta}{1-\rho}[\rho+\alpha(\delta-\rho)] \Delta c_{t+1}-\frac{1-\theta}{1-\rho}(\rho-\delta) \Delta l_{t+1}+\frac{\rho-\theta}{1-\rho} r_{W, t+1},
$$

where lowercase letters denote the log of uppercase letters.

Using Eq. (B-9), the covariance between $m_{t+1}$ and the stock/portfolio return is:

$$
\begin{aligned}
\operatorname{Cov}\left(m_{t+1}, R_{i, t+1}\right) & =-\frac{1-\theta}{1-\rho}[\rho+\alpha(\delta-\rho)] \operatorname{Cov}\left(\Delta c_{t+1}, R_{i, t+1}\right) \\
& -\frac{1-\theta}{1-\rho}(\rho-\delta) \operatorname{Cov}\left(\Delta l_{t+1}, R_{i, t+1}\right)+\frac{\rho-\theta}{1-\rho} \operatorname{Cov}\left(r_{W, t+1}, R_{i, t+1}\right) .
\end{aligned}
$$

According to Yogo (2006), we can approximate $M_{t+1}$ as:

$$
\begin{aligned}
-\frac{M_{t+1}}{E\left[M_{t+1}\right]} & =-1-m_{t+1}+E\left[m_{t+1}\right] \\
& =a+b_{1} \Delta c_{t+1}+b_{2} \Delta l_{t+1}+b_{3} r_{W, t+1},
\end{aligned}
$$


where $a=-1-b_{1} E\left[\Delta c_{t+1}\right]-b_{2} E\left[r_{W, t+1}\right]-b_{3} E\left[\Delta l_{t+1}\right], b_{1}=\frac{1-\theta}{1-\rho}[\rho+\alpha(\delta-\rho)], b_{2}=\frac{1-\theta}{1-\rho}(\rho-\delta)$, and $b_{3}=\frac{\rho-\theta}{\rho-1}$.

Using Eqs. (B-8), (B-9), (B-10), and (B-11), the beta representation is:

$$
E\left[R_{i}-R_{f}\right]=\gamma_{c g} \beta_{i, c g}+\gamma_{m k t} \beta_{i, R_{W}}+\gamma_{l i q} \beta_{i, l i q}
$$

where $\beta_{i, c g}$ denotes the consumption beta, $\beta_{i, R_{W}}$ denotes the return to wealth beta, and $\beta_{i, l i q}$ denotes the liquidity beta; $\gamma_{c g}, \gamma_{m k t}$, and $\gamma_{l i q}$ are the prices of consumption risk, market risk, and liquidity risk. 